\title{
التغير في تكرار الأمواج المغلقة (مراكز منخفضات القطع) ومدة سيطرتها فوق العرلق خلال فصل الثتاء
}

\author{
أ.م.د. علي غليس ناهي السعيدي \\ جامعة ميسان/ كلية التربية
}

المقدمة

لقد اسهمت التطورات التقنية الحديثة في مجال الأرصاد الجوية واستخدام الحواسيب الإكترونية،

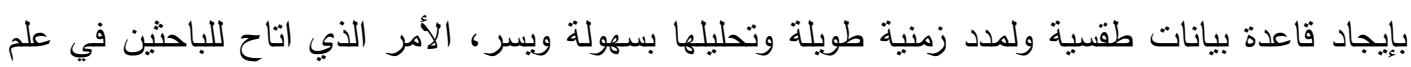

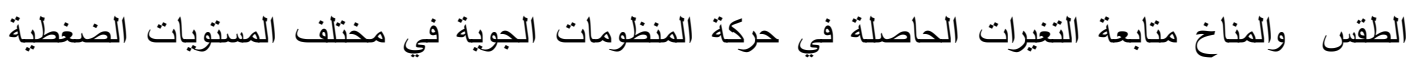

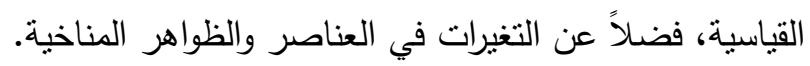

إنَ الامواج الهوائية المغلقة إحدى أهم المنظومات الجوية المؤثرة في الظروف الطقسية السطحية، ويتطلب دراستها معرفة جيدة بظواهر طبقات الجو العليا (كالأخاديد، الإنبعاجات، مرتفعات ومنخفية الهنات

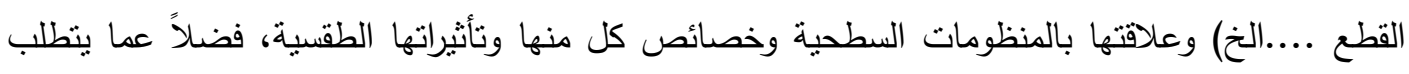

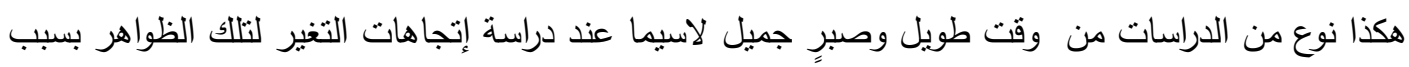

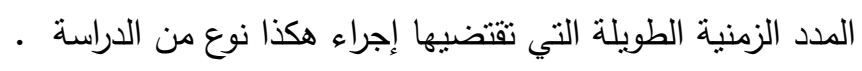

لقد تتاول الباحث دراسة الأمواج المغلقة التي تضمنت (منخفضات ومرتفعات القطع) إلا أنه اختار

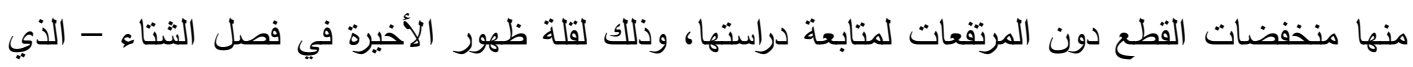

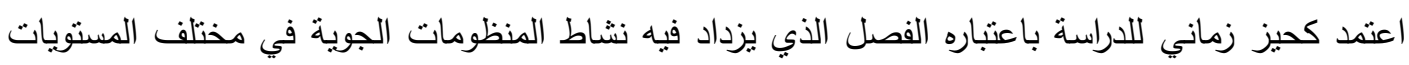
الضغطية - بسبب قوة التبادل في الطاقة الحرارية في هذا الفصل بين المناطق القطبية والمدارية - ولكون منخفضات القطع ينجم عنها ظروف طقسية حادة. 
لقد اقتضت الضرورة العلمية اولاً الكثف عن تكرارات ومدة سيطرة الأمواج الهوائية فوق العراق في المستوى الضغطي ( . .0) ومايرافقها من المنظومات الجوية السطحية في المستوى الضغطي القياسي ( . . ( ) هكتوباسكال ، فضلاً عن ذلك وبغية التأكد من فعالية ومدى تعمق تلك المنظومات في المستوى الضغطي ( . . . (1) هكتوباسكال فقد درس الباحث المنظومات المتعقة منها تلك التي تظهر في المستوى

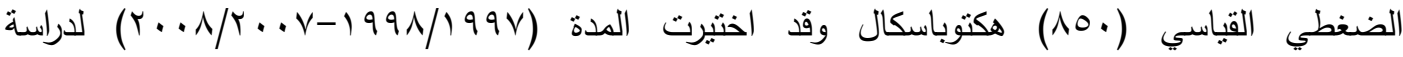
المستويات أعلاه ولرصدنين ( . .، ب ( )بالتوقيت الدولي GMT ، أي الساعة الثالثة صباحا والساعة الثالثة مساءاً ويمنل ذلك هدفاً ثانوياً للاراسة، أقتضت الضرورة العلمية كما ذكرنا تتاوله ثم دراسة التغيرات التي

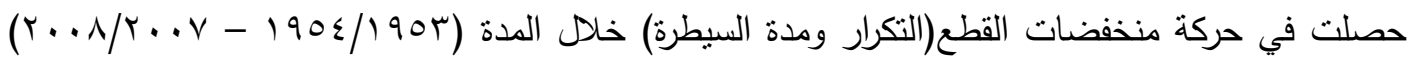
الذي يُعد الهدف الرئيس من الدراسة.

لقد أتخذ الباحث من مراكز الموجة المغلقة (منخفضات القطع) الظاهرة فوق العراق مستبعداً بذلك امتداداتها لمتابعة التغير في نكرارات ومدد سيطرة الموجة المغلقة فوق العراق، كون ظهور مراكز منخفضات القطع يؤثر على الغالبية العظمى من مساحة العراق (منطقة الدراسة) إن لم تكن كلها، هذا من ناحية ومن ناحية اخرى بغية التخلص من التشويشات التي يمكن أن تحصل في مسألة أقتران الموجة المغلقة بالمنظومات الضغطية التي نظهر في المستوى (. . (1) هكتوباسكال لأن تلك الامتدادات لا تغطي في أغلب الاحوال كل او أغلب مساحة العراق.

\section{أولاًا مشكلة البحث: تتلخص مشكلة البحث في:}

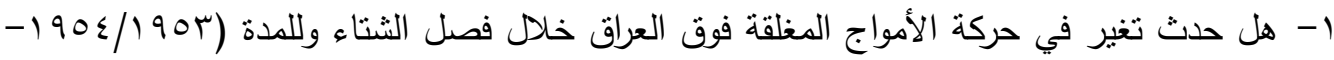

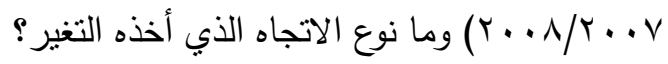

r- ما نوع المنظومات الضغطية في المستوى الضغطي القياسي( . . (1) هكتوباسكال؟ وما نسبة المتعمق منها (الظاهرة في المستوى الضغطي م10 هكتوباسكال) التي يقترن ظهورها بالأمواج المغلقة ؟. 


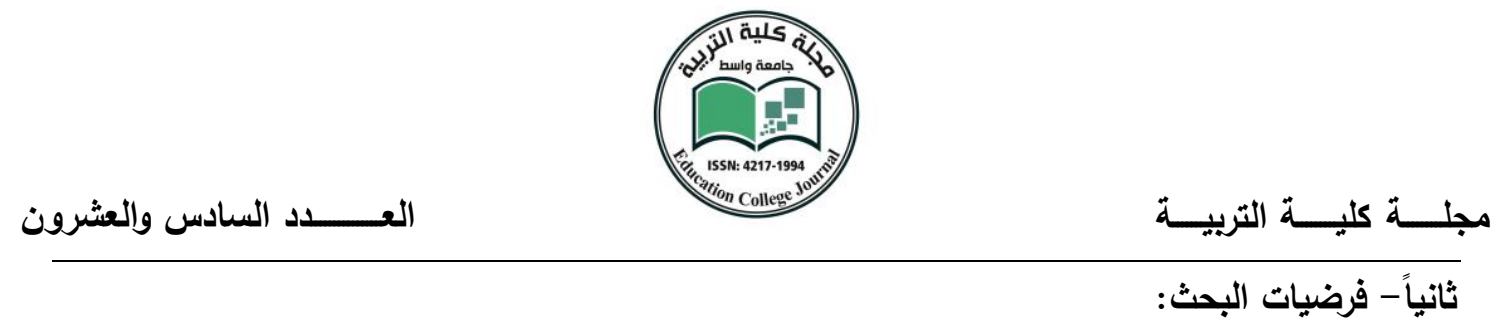

1- يفترض الباحث وجود تغير في حركة الأمواج المغلقة فوق العراق نحو التزايد

ץ- أنً أكثر المنظومات الضغطية التي يقترن وجودها في المستوى( . . . 1) هكتوباسكال بالأمواج المغلقة هي المنخفضات الجوية وهي أكثر المنظومات الجوية تعمقاً (تظهر المنظومات في ذات الوقت في

$$
\begin{aligned}
& \text { المستوبين } \\
& \text { ( . . . . . . هكتوباسكال). } \\
& \text { ثالثاً - أهداف البحث : }
\end{aligned}
$$

1- يهدف الباحث إلى إستكثاف طبيعة التغير في تكرار ومدة سيطرة الأمواج المغلقة فوق العراق. ץ- معرفة نوع ومدة المنظومات الضغطية السائدة في مستوى الضغطي ( (... (1) هكتوباسكال المقترن ظهورها بظهور الموجة المغلقة فوق العراق ومدة المتعمق منها في المستوى الضغطي (م0.) هكتوباسكال.

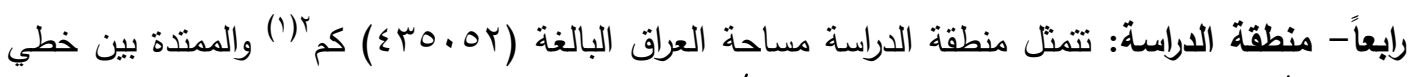

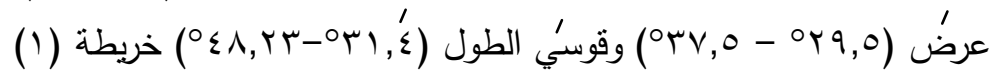




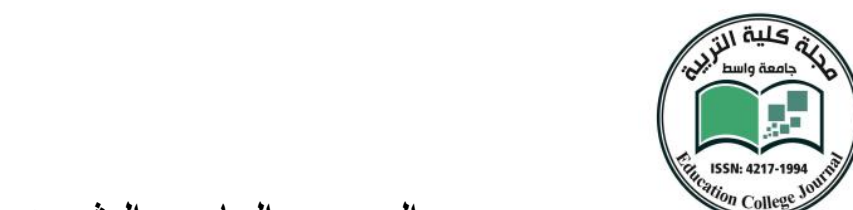

\section{خريطة (1)}

\section{منطقة الدراسة}

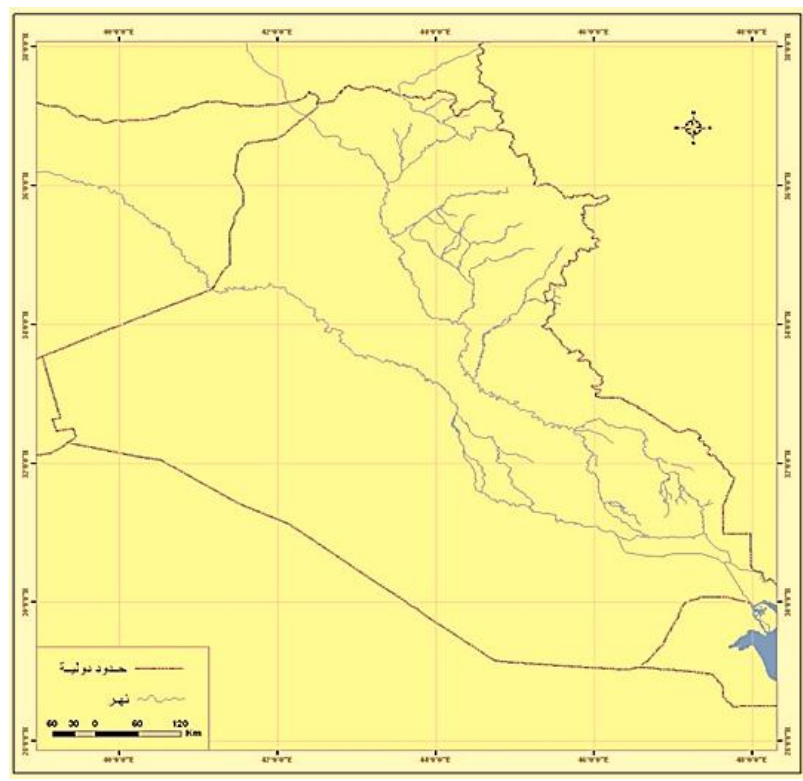

المصدر : الهيئة العامة للمساحة، خريطة العراق، بغداد: V. Y.

\section{خامساً - طريقة اجراء البحث}

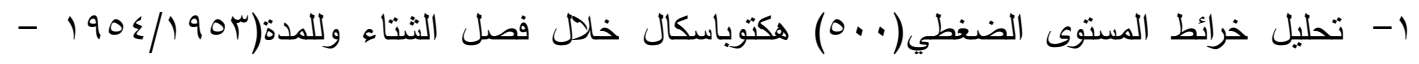

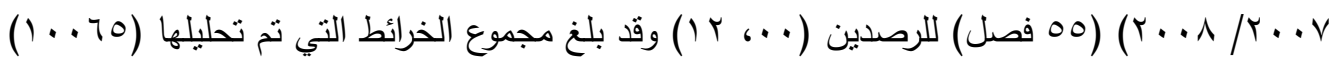
خريطة.

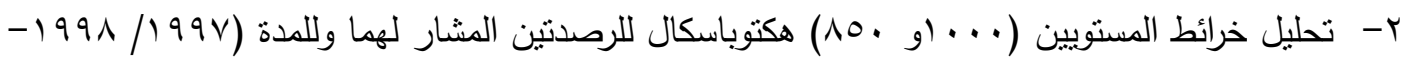

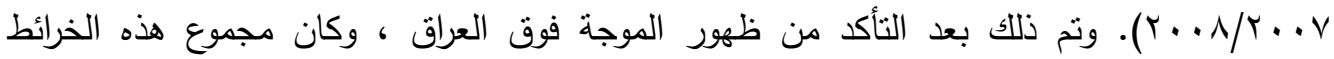


للمستوبين (Yr) خريطة ثقريبا وبذلك يكون مجموع الخرائط التي تم تحليلها في هذه الدراسة مجلــــة كليــــة التربيــــة

$$
\text { (19V) }
$$

ب- استخدام بعض الوسائل الكمية للكثف عن التغير في تكرار ومدة سبطرة الموجة المغلقة فوق العراق

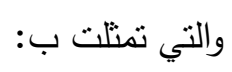

أ- طريقة الاوساط المتحركة للكثف عن التغير في تكرار ومدة سيطرة الموجة المغلقة فوق العراق. ب- استخدام طربقة فرق المتوسط ومعامل الاختلاف، ولأجل ذلك فقد تم تقسيم مدة الدراسة إلى خمس طرس

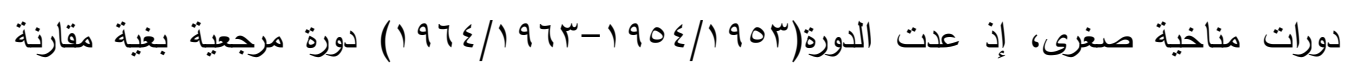
الدورات

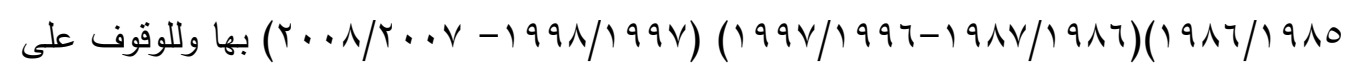
التغير في متوسطاتها من ناحية ومن ناحية أخرى معرفة التباين في معامل اختلافها ومدى تجانس قيمها وتطرفها لكل من متغيري (التكرار ومدة السيطرة) للأمواج الهوائية المغلقة فوق العراق ، باستخدام

$$
\text { البرنامج الإحصائي (spss). }
$$

\section{سادساً - الاراسات السابقة:}

لقد تتاولت الأمواج المغلقة من قبل باحثين اخرين في دراستهم وابحاثهم التي تتوعت اهدافها ومشاربها فقد نتاول الزنكنة(r)الحاجز الضغطي (Blocking) معلاً سبب نشأته إلى تحرك الأمواج القطبية العليا نحو في دئم خط الاستواء، مما يؤدي إلى ظهور منخفضات قطع cut off low بينما بتسبب انحناء خطوط التساوي الجهدي نحو الشرق إلى ظهور مرتفعات القطع cut off High. في حين اشار الهذال(ऍ) إلى إن ظاهرة الحاجز الضغطي هي عبارة عن نتوه في التيارات الهوائية في الاقسام العليا والوسطى من طبقة التروبوسفير، وعزى الباحث هذا التشوه إلى انتقال هواء الغربيات إذ يؤدي ذلك إلى تشكيل أمواج مغلقة (منخفضات ومرتفعات قطع)، أما الدزيني(ء) فقد أشار إلى تطور الرياح الغربية إلى أمواج قصيرة تتحول إلى أمواج مغلقة (منخفضات ومرتفعات قطع) عليا وأثنار إلى أهميتها في نقل الطاقة بين مناطق العروض العليا والدنيا، أما السامرائي وزميلته(ه) فقد عزيا ارتفاع درجات الحرارة صيفاً وشتاءاً في العام (ب99 ()) إلى ظهور الحاجز الضغطي فوق البلاد (مرتفع القطع) مما اعاق ثقدم الاخاديد ومن ثم امتداد لسان من الهواء الحار من الجنوب والجنوب الثرقي فوق العراق، أما عبد الرضا(؟) فقد اشارت إلى حصول نطور في الامواج الطويلة 
يؤدي إلى انفصالها مكونة منخفضات قطع إعصارية واخرى ضد إعصارية، أما الباحث الجوراني(ل) فقد توصل إلى إن أشهر (كانون الاول، كانون الثاني وشباط) قد شهدت تزايداً في تكرار ومدة بقاء الاخاديد

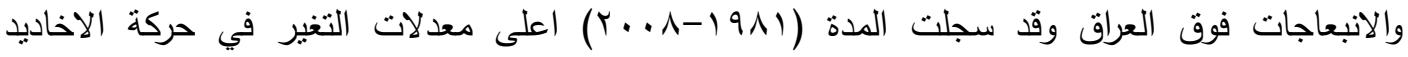
والانبعاجات.

إن أهم دراسة منفصلة عن الأمواج المغلقة كانت دراسة الثمري(^) التي تتاول بها الحاجز الضغطي إذ تبين أن أعلى تكرار للحاجز الضغطي والذي تمثل بالموجة المغلقة (منخفض القطع) فوق العراق كانت في اثشر (كانون الاول، كانون الثاني وشباط) وقد وجد إن هناك علاقة عكسية بين الحاجز الضغطي (منخفض القطع) وسرعة الرياح، بينما كانت هنالك علاقة ارتباط طردية بين انخفاض معدلات دراجات الحرارة

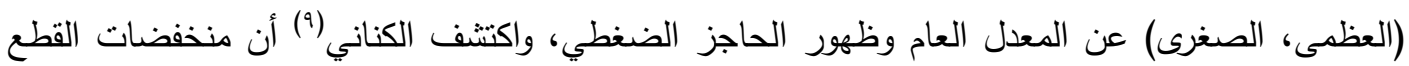
تُعد أهم المنظومات الجوية الذي ينجم عن نواجدها تساقط امطار قياسية في عموم العراق، وقد وجد إن تلك المنظومات تقترن في الغالب بوجود منخفضات سطحية مسؤولة بشكل مباشر أو غير مباشر عن التساقط المطري القياسي منل (المنخفضات المتوسطة، المنخفضات السودانية، فضلاً عن المنخفضات المندمجة) وقد عزى الباحث ذاته في دراسة لاحقة له(·) إلى أن الامطار القياسية التي حدثت في مايس با ـ ب ترجع إلى ملى

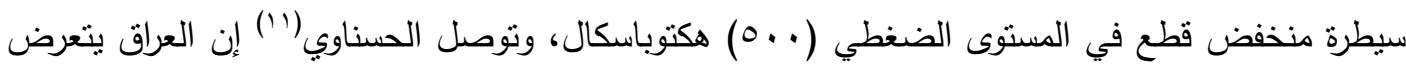
في الفصل الجاف الى الأمواج المغلقة وأن شهر أب أكثر الثهور تكراراً، علاوة على ما تقدم هنالك دراسات عالمية كثيرة حول الموضوع من بينها دراسة العالم kevin E. trenberth واخرون ( r') التي توصلوا بها الى ان احد اهم اسباب ارتفاع درجات الحرارة ومانجم عنه من حرائق في روسيا عام • 1 · بهو سيطرة حاجز

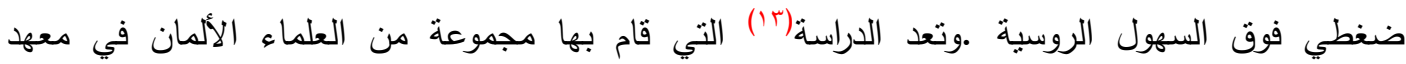
Dim coumou الالماني بقيادة العالم Potsdam Institute for Climate Impact Research والمنشورة في مجلةProceeding of the National Academy of science الامريكية من افضل الدراسات ذات الصلة بالتغير المناخي إذ اشارت إلى ان التغيرات الحادة التي تسبب الكوارث الطبيعية (كارتفاع درجات الحرارة او انخفاضها، الأمطار الغزيرة والأعاصير المدمرة) أنما تعود إلى ان الرياح التي تتحرك على شكل أمواج دائرية أو حلقية هي في تزايد مستمر عكس ما كان عليه الحال في السابق ثم عاد

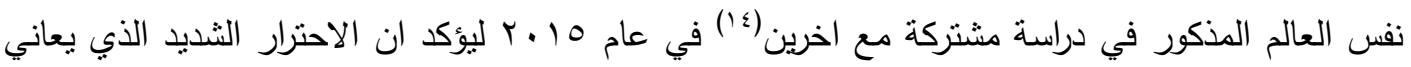


منة القطب الشمالي يمكن أن يؤثز على الدورة الهوائية في منطقة العروض الوسطى كما اشار الى التغيرات الحاصلة في أمواج Rossby ، ومما هو جدير بالذكر إن بغداد شهدت في |

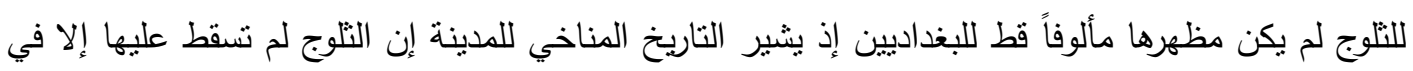

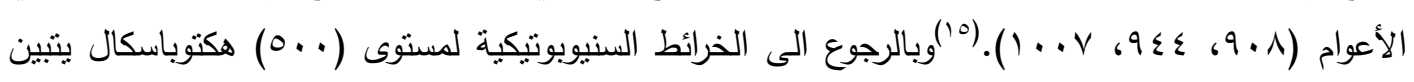
وجود موجة مغلقة من نوعٍ منخفض القطع يسيطر على العراق بينما على السطح كان بسيطر المرتفع

$$
\text { السيبيري على شمال ووسط العراق ومن الجنوب المنخفض السوداني. }
$$

\section{تمهيد:}

الأمواج المغلقة هي عبارة عن دوامات هوائية كبيرة ذات سرعة دوران عالية ليبدأ نشؤها من تموجات كبيرة الحجم في نطاق الرياح الغربية التي قد تتحول كلياً إلى دوامات مغلقة مشكلة من مراكز انخفاضات

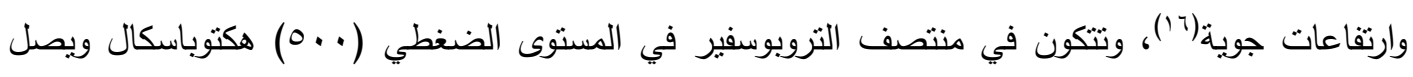

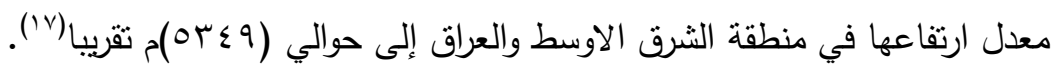

وقد ينجم عن حركة الأمواج الطويلة والتباين في الفروقات الضغطية ، تبادل للطاقة الحركية والحرارية للهواء بين الاجزاء المختلفة للغلاف الجوي إذ يتم نقل الهواء الحار شمالاً (عندما يتقدم انبعاج او مرتفع قطع) أو نقل الهواء البارد نحو الجنوب (عندما يتقدم اخدود او منخفض قطع)(')، كما تسمى الأمواج المغلقة ايضاً بالأمواج المتطورة كونها نطورت من الأمواج الطويلة وهي تأخذ نمطين أساسبين (نمط الموجة المغلقة على ألى شكل منخفض قطع علوي، وموجة أخرى مغلقة ايضاً على شكل مرتفع قطع علوي، ولها أهمية عظبمة كونها تقوم بنقل الطاقة بين العروض العليا والدنيا بفعالية أكثر من الأمواج الطويلة أو القصيرة(19) وكما أشرنا سابقاً وخلاصة القول إن الأمواج المغلقة عبارة عن منخفضات ومرتفعات قطع تتفصل عندما يزداد إنحناء الأخدود والأنبعاج وعند أقترابه دن شكل الحرف ( U )، وأهم الظروف التي تساعد في إنفصال الموجة هو شدة التباين الحراري بين الكتلة المتقدمة ، سواء من الثمال نحو الجنوب أو العكس، مع الكتلة الهوائية المسبطرة على المنطقة ، كما هو الحال في حالة تقدم إخدود من الهواء البارد نحو شرق البحر المتوسط والذي سرعان ما يتحول إلى موجة مغلقة (منخفض قطع) يتجه نحو الثرق كما سنبين لاحقا. 
يتبين من الجدول (1) والثكل (1) ان معدل نكرار الموجة المغلقة (مركز منخفض القطع ) خلا

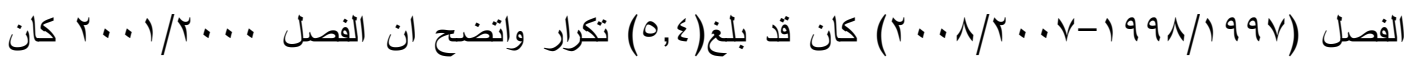
اكثر الفصول تكراراً لمرور الموجة المغلقة فوق العراق إذ يبلغ (0) نكراراً وقد شكل بذلك نسبة بلغت

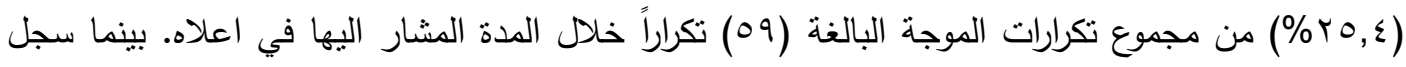

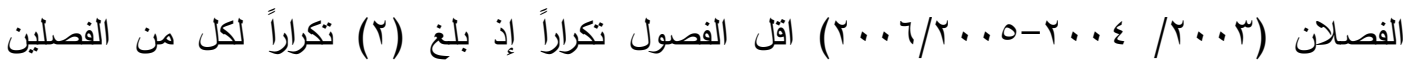
المذكورين انفاً وبنسبة (ع,r\%) من مجموع تكرارات الموجة المشار اليها سابقاً.

ان تزايد تكرارات الموجة يعتمد على مدى توافر الظروف المناسبة لتطورها والتي اهمها زيادة تقعر الأخاديد الهوائية الناجم بفعل شدة التباين بين درجة حرارة الهواء في المنطقة وهواء الاخدود القادم.

أما بالنسبة إلى مدة سيطرة الموجة المغلقة فقد بلغ معدل مدة السبطرة(7) يوماً (الجدول والثكل

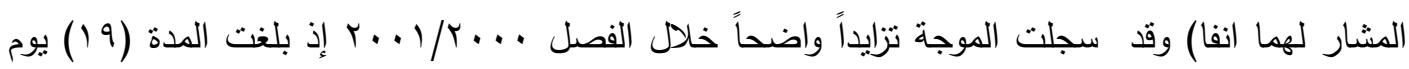

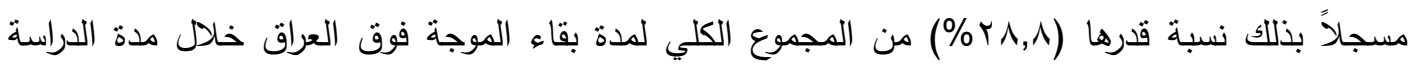

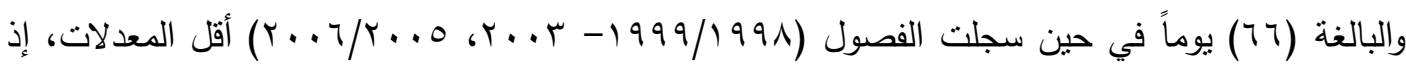
بلغت (r,0) يوماً لكل من الفصول انفة الذكر وبذلك كونت نسبة قدرها (^,r\%) من المجموع الكلي لمدة سبطرة الموجة فوق العراق.

إن مدة سيطرة الموجة فوق العراق نتأثر بوجود الانبعاج إلى الثرق منها وهو ما يعمل على عرقلة تقدها نحو الثرق ويبطئ من حركتها، أو يعمل على إنحراف مسارها نحو الجنوب الشرقي مما يجبرها - أي إي الموجة - على إتباع مسارٍ ممتٍّ داخل الاراضي العراقية من الثمال الغربي نحو الجنوب الثرقي، وفي كلا الحالتين يزيد ذلك من مدة بقائها فوق العراق، فضلاً عما تقدم، فأن تكون وظهور الموجة فوق العراق أو بالقرب منه له أثز ايضاً على مدة بقاء الموجة فوقه، مع الأخذ بنظر الأعتبار الحالتين المشار لهما أعلاه.

* اي اشارة لاحقة للموجة المغلقة نعني بها مركز منخفض القطع. rVA 
العـــــــد السادس والعشرون

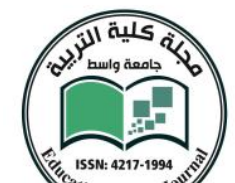

إن التباين في نكرار ومدة سيطرة الموجة قد انعكس على مدى ظهور المنظومات في المستوى الضغطي ( . . (1) هكتوباسكال والمقترن ظهورها عادة بظهور الموجة وتطورها وتعمقها في المستوى الضغطي(م) مهو ما سنبينه لاحقاً.

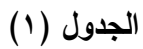

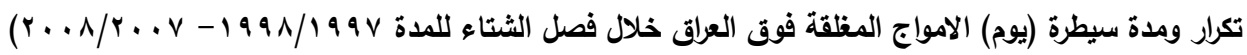

\begin{tabular}{|c|c|c|}
\hline مدة السيطرة & التكرار & \\
\hline$r, 0$ & $\varepsilon$ & $1991 / 1998$ \\
\hline$r, 0$ & r ( - n & $1999 / 1991$ \\
\hline$\varepsilon$ & $\varepsilon$ & $r \ldots / 1999$ \\
\hline 19 & 10 & $r \ldots 1 / r \ldots$ \\
\hline r & 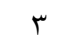 & $r \ldots r / r \ldots l$ \\
\hline r & 0 & $r \ldots r / r \ldots r$ \\
\hline$r, 0$ & r & $r \ldots \varepsilon / r \ldots r$ \\
\hline 7 & 0 & $r \ldots o / r \ldots \varepsilon$ \\
\hline$r, 0$ & r & $r \ldots r / r \ldots 0$ \\
\hline $1 \cdot, 0$ & 9 & $r \ldots r / r \ldots r$ \\
\hline 9,0 & V & $r \ldots \Lambda / r \ldots v$ \\
\hline 77 & 09 & المجموع \\
\hline
\end{tabular}

المصدر: من عمل الباحث بالاعتماد على الموقع الأكتروني: www.vortex plymouth.edu . 


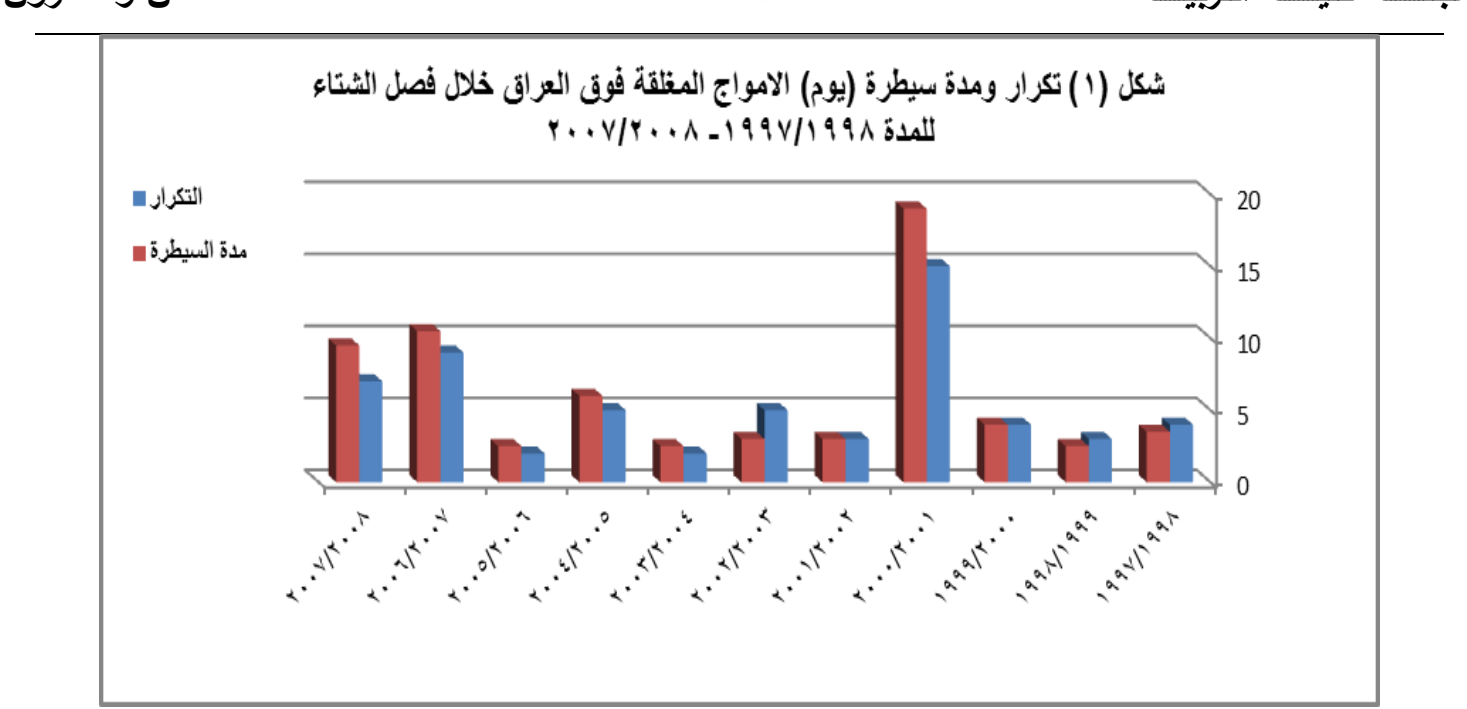

المصدر: من عمل الباحث بالاعتماد على الجدول (1).

ثانياً: مدة سيطرة المنظومات الضغطية عند المستويين ( . . . او • مـ) هكتوباسكال المرافقة

لكأمواج المغلقة في العراق

يتضح من الجدول (r) والثكل (Y) إن المنخفض السوداني يأتي في مقدمة المنظومات الضغطية التي يقترن وجودها بظهور الموجة المغلقة فوق العراق، والظاهرة في المستوى الضغطي القياسي ( (.0)

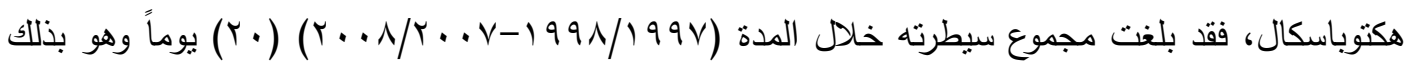

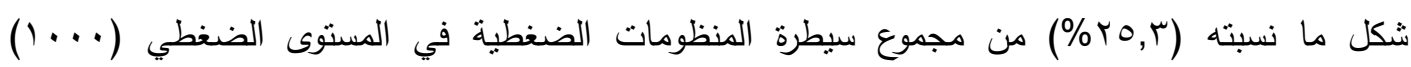
هكتوباسكال، خلال فصل الثناء (اشهر كانون الاول، كانون الثاني وشباط) والبالغة (V9) يوماً، إذ عادة ما يقوم المنخفض السوداني بأبعاث امتداداته إلى العراق متزامنة وسيطرة الموجة المغلقة مبتدأه - اي امتدادات المنخفض السوداني- بدخول العراق من الجهة الجنوبية الغربية والغربية مسيطرة بذلك على المنطقتين

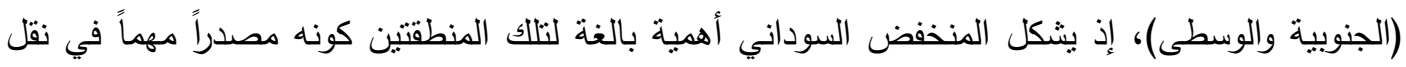

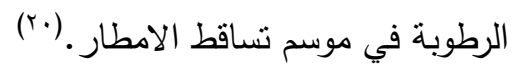


يتعمق المنخفض السوداني احياناً فوق أجواء العراق فقد بلغت مدة سيطرته في المستوى الضغط

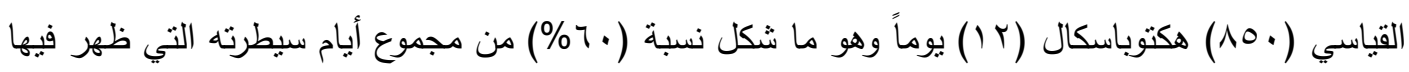

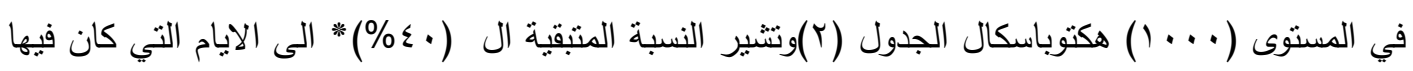
المنخفض ضحلا -اي يسيطر فقط على السطح دون أن يتعمق وصولا للمستوى الضغطي هـ (10.)

بينما شكلت تلك الايام - اي الـ با يوماً - ما نسبته .ب \% من مجموع ايام سيطرة المنظومات الاخرى والبالغة (•ء) يوماً والتي بلغت المستوى الضغطي (•○) هكتوباسكال. إذ تعمل الرياح الباردة لمنخف القطع(لاسيما عند ظهورها في المستوى الضغطي . . هكتوباسكال) على تشتيت الرياح الدافئة للمنخفض السوداني مما يقلل من مدة بقاهه متعمقاً في المستوى (م0.1) هكتوباسكال فضلاً عن كونه منخفض ضحل أصلاً لبعده عن مركزة الرئيس، لذا كانت نسب تعمقه أقل بالمقارنة مع المنخفض المتوسطي وكما سيتضح.

أن المنخفض السوداني يندمج احياناً مع المنخفض المتوسطي الذي عادة ما تقوم الموجة المغلقة بدفعه امامها فوق العراق مما يؤدي إلى حدوث اندماج مع المنخفض السوداني، ومما يساعد في ذلك وجود مرتفع حاجزي على السطح (Blocking) والذي يقوم بعرقلته عندما يتقدم المنخفض المتوسطي نحو الثرق.

لفد بلغت مدة سيطرة المنخفض المندمج (1,0 1 ) يوماً في المستوى الضغطي ( (. . ( ) هكتوباسكال والذي شكل نسبة (1, (1\%) من مجموع سيطرة المنظومات الجوية عند المستوى المشار اليه أعلاه. بينما

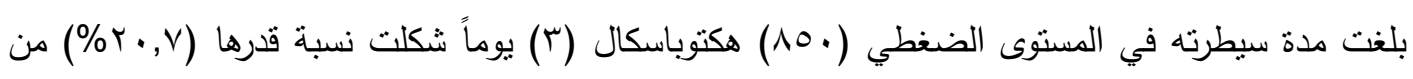


(الجدول(r) (

مدة سيطرة (يوم) المنظومات الضغطية السطحية والمتعقة منها خلال المدة ( (

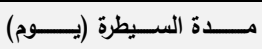

منظومة

r.

r $\quad$ o

$.0 \quad r$

1.0

$7.0 \quad 1.0$

I . .0 r.

.0

I ..०

1.

\begin{tabular}{l|l|l}
\hline & r
\end{tabular}

..०

9.0

\begin{tabular}{l|l|l}
.0 & .0 & $r .0$
\end{tabular}

. .

$+$

r

.0

r.o

$+$

(

$\varepsilon$

r.o

r.o

r.o

1.0

$-$

$r$

. .0

$-$

$r$

\begin{tabular}{|c|c|}
\hline .0 & - \\
\hline- & - \\
\hline
\end{tabular}

1

\begin{tabular}{l|l|l|}
\hline & 1.0 & \\
\hline & - &
\end{tabular}

\begin{tabular}{|c|c|c|c|c|c|c|}
\hline &. .0 & - & - & - & - & - \\
\hline 1 & - & - & - & - & - & - \\
\hline$r$ & - & - & - & - & - & - \\
\hline
\end{tabular}




\begin{tabular}{|c|c|c|c|c|c|c|c|c|c|c|c|c|}
\hline \multicolumn{9}{|c|}{ المنظومات الضغطية المتعقة } & \multicolumn{4}{|c|}{ 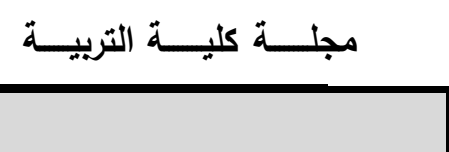 } \\
\hline Ir & 1 & r.o & .0 & - & - & - & 1.0 & 0 & 1 & - & .0 & \\
\hline$r$ & - &. .0 & .0 & 1 & - & 1 & - & - & - & - & - & \\
\hline $1 \leq$ & r & 1.0 & .0 & r & .0 & 1.0 & .0 & $r$ & .0 & 1 & $r$ & \\
\hline r.० & 1.0 & - & - & - & - & - & - & $r$ & - & - & - & \\
\hline .0 & - & - & - & - & - & - & - & - & - & .0 & - & \\
\hline r. & .0 & r & - & 1 & - & - & - & - & - & - & - & \\
\hline .0 & - & - & - & .0 & - & - & - & - & - & - & - & \\
\hline T.O & - & 1.0 & - & - & - & - & - & - & - & - & 1 & \\
\hline .0 & - & - & - & - & - & - & - & - & - & - & .0 & لهضبة \\
\hline & & & & & & & & & & & & لايرانية \\
\hline
\end{tabular}

المصدر: من عمل الباحث بالاعتماد على الموقع الألكتروني: www.vortex plymouth.edu . 
العـــــــد السادس والعشرون

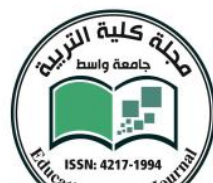

ation College 3

مجلـــة كليــــة التربيـــة

شكل (ץ) مدة سيطرة (يوم) المنظومات الضنطية السطحية والمتعقة منها خلال المدة

$(\%+v / 4+.199 v / 1991)$

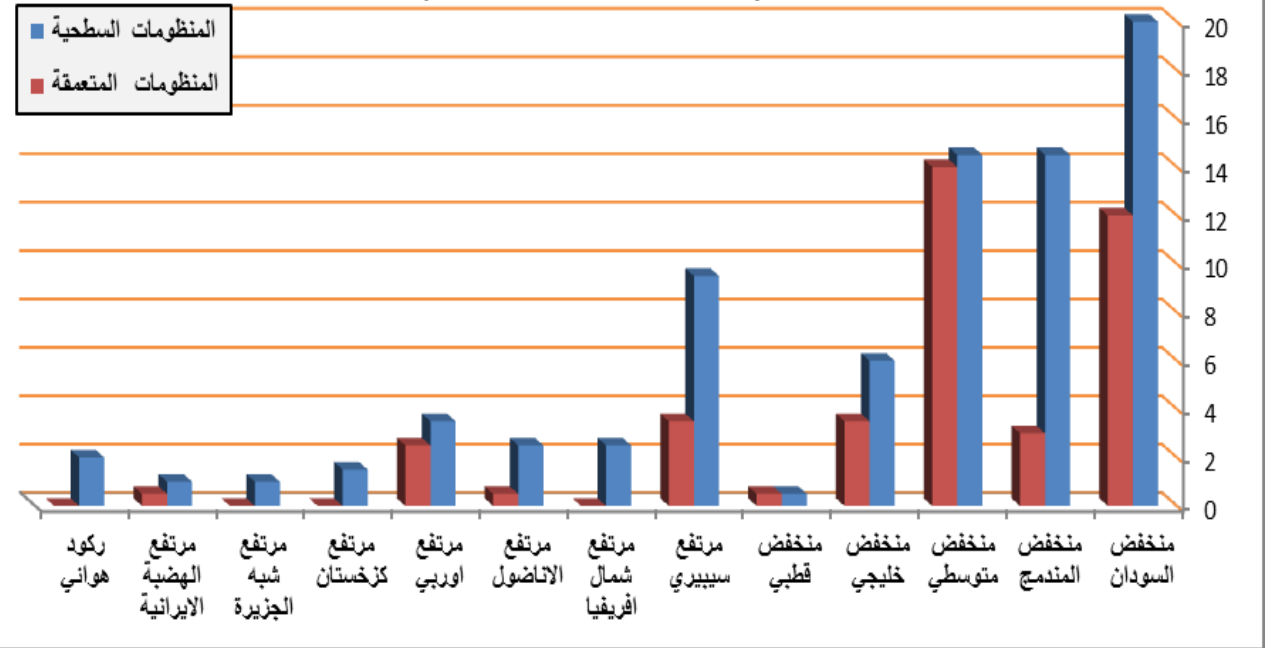

المصدر : من عمل الباحث بالاعتماد على جدول (r)

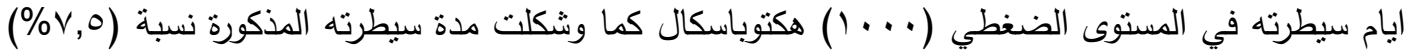
من مجموع أيام سيطرت المنظومات المتعمقة الأخرى وللمنخفض المندمج تأثثرات طقسية أهمها التساقط المطري وحدوث عواصف البرق والرعد وتساقط البرد.

أما بالنسبة إلى المنخفض المتوسطي فقد بلغت مدة سيطرته خلال المدة المذكورة (, ع ( ) يوماً ايضاً

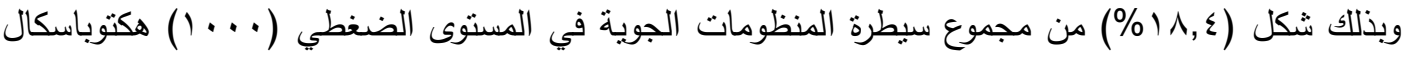
ويتعمق المنخفض المتوسطي في أغلب أيام ظهوره إذ بلغت مدة سيطرته من المستوى الضغطي (م०) هكتوباسكال (ع (1) يوماً مشكلاً نسبة قدرها (7,7 (9\%) من مجموع أيام سبطرته في المستوى الضغطي

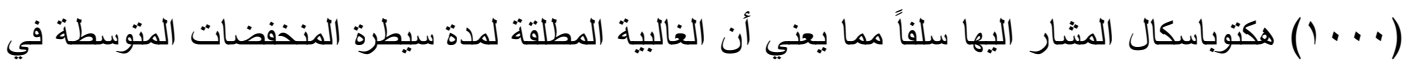

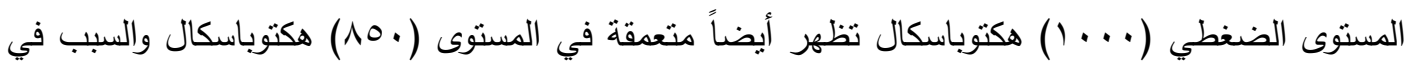
ذلك يرجع إلى قرب منطقة تكون المنخفض المتوسطي من المنطقة التي تتكون عليها الموجة المغلقة (منطقة 
الاضطراب الجوي العلوي التي قد تتعمق لتصل أحيانا للسطح لتكون بما يمكن وصفه بالمنخفض الجوي النشط جداً الذي يؤدي الى تساقط النلوج في الدول المجاورة كالاردن وسوريا) أو لربما تكون ذات منطقة تكون واحدة (كما هو الحال في شرق المتوسط)، مما يؤدي إلى زيادة فعالية المنخفض المتوسطي ، لذا فقد شكلت تلك المدة المشار لها سابقاً نسبة (r,7r\%) من مجموع مدة سيطرة المنظومات الأخرى في المستوى ئرى الضغطي (10) هكتوباسكال وهو بالحقيقة مؤشر مهم على مدى فعالية هذه المنظومة ، وللمنخفض مده مده المتوسطي تأثثرات طقسية فوق العراق تتمنل بحدوث حالات عدم الاستقرار الجوي (كالبرق والرعد وتشاقط مهوى الامطار والبرد) فضلاً عن تقلب الرياح (r.").

علاوة على ما تقدم نأتي منخفضات أخرى بمدد سيطرة أقل مثل منخفض الخليج والذي يتكون عادة من تقدم خلية مهاجرة من المنخفض السوداني نحو الخليج العربي (فوق شمال الخليج ووسطه) والامر الذي يؤدي إلى تعمق تلك الخلية باعثة امتداداتها واحياناً متزحزحة بمركزها نحو جنوب العراق، وقد بلغت مدة سيطرته (T) يوماً شكلت نسبة قدرها (T,T\%) من مجموع سيطرة المنظومات الجوية في المستوى الضغطي

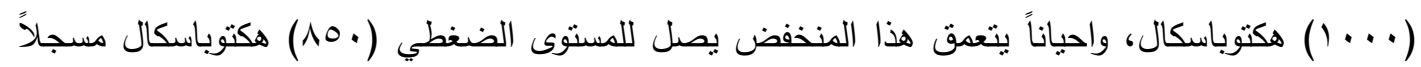

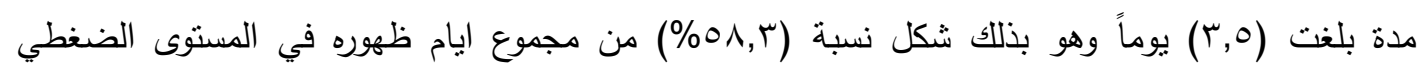

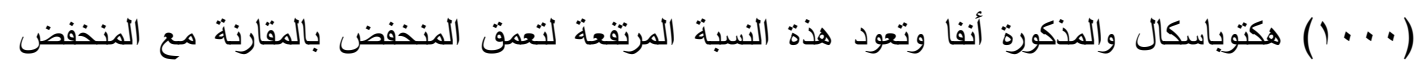
السوداني الأب الشرعي للمنخفض الخليجي لأعادة تفعيله فوق الخليج العربي اذ تزداد طاقتة ويتعق بينما

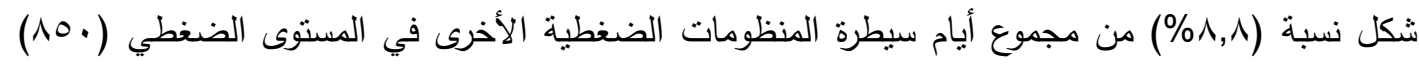
هكتوباسكال. ثم جاء المنخفض القطبي بمدة زمنية ضئيلة جداً.

مما تقدم يتبين إن أكثر المنخفضات ظهوراً في المستوى الضغطي (. . (1) هكتوباسكال هو المنخفض السوداني ويعود ذلك إلى بطئ حركة المنخفض السوداني الذي غالباً ما تكون إمتداداته ضحلة لبعدها عن المركز او لضحالة خلاياه المنفصلة التي تصل الى العراق أو تقترب منه. كما إن المنخفض عادة ما يسيطر على مساحة كبيرة من العراق وذللك في المنطقتين الوسطى والجنوبية لذلك بيتغرق وقتاً أطول في لأكمال انسحابه منها بخلاف المنخفض المتوسطي الذي تكون حركته اكثر سرعة لقربه من منطقة الاضطراب الجوي العلوي كما أثرنا قبل قليل، وإختراقه لمساحة أقل من العراق - غالباً ما نكون المنطقة 
الثمالية - لذا تكون مدة بقاءه فوق العراق اقل مقارنة بالمنخفض السوداني إلا إنه اكثر تعمقاً من المنخفض

أما المرتفعات الجوية التي يقترن وجودها مع وجود الموجة المغلقة فيأتي في مقدمتها المرتفع السيبيري الذي بلغت مدة سيطرته (9,0) يوماً شكلت نسبته (., (Y\%) من مجموع مدة سيطرة المنظومات الجوية الاخرى في المستوى الضغطي ( . . (1) هكتوباسكال والمشار اليها سابقاً. بينما بلغت مدة ظهوره في

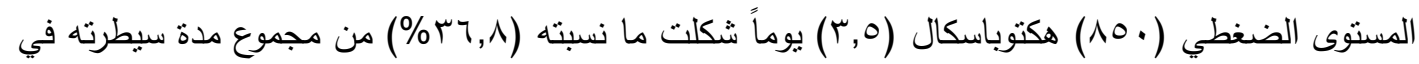

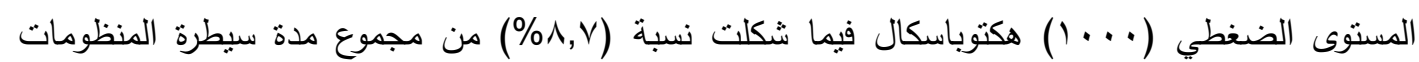
الجوية الأخرى عند المستوى الضغطي (م.0) هكتوباسكال. ثم يأني المرتفع الأوربي بالمرتبة الثانية بعد

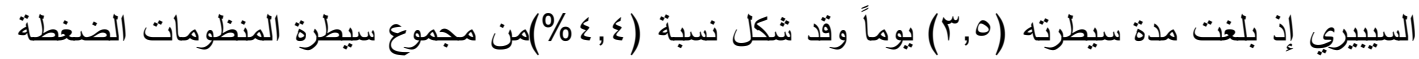

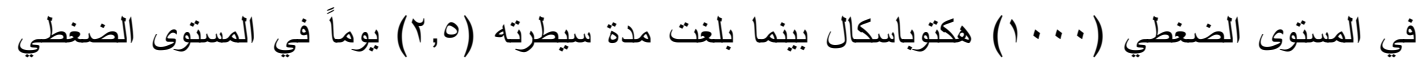

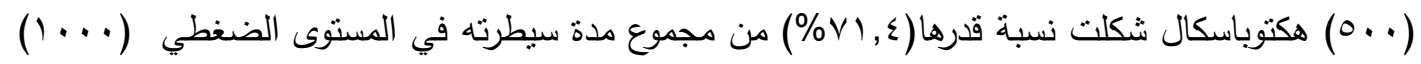
هكتوباسكال في حين شكل نسبة (ז,7\%)من مجمع مدة سيطرة المنظومات الجوية الأخرى المتعمقة في مدهي المستوى الضغطي (•.1) هكتوباسكال .ثم جاء المرتفعان (شمال أفريقيا ،الاناضولي) بمدة سيطرة بلغت (Y,0) يوماً لكل منهما شكلت ما نسبة (r,Y\%) من مجموع المنظومات الجوية الأخر ، ويبدو إن مرتفع شمال افريقيا لم يظهر في المستوى الضغطي ( (10) هكتوباسكال إذ ظهر المرتفع الأناضولي فقط فقد بلغت مدة سيطرته ( 0, •) يوماُ شكلت نسبه قدرها ( •r\%) من مجموع مدة سيطرته في المستوى الضغطي

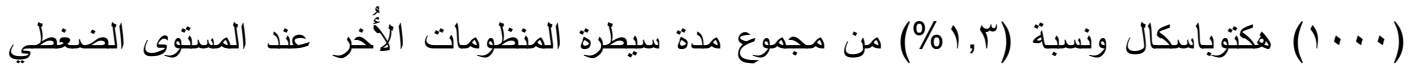

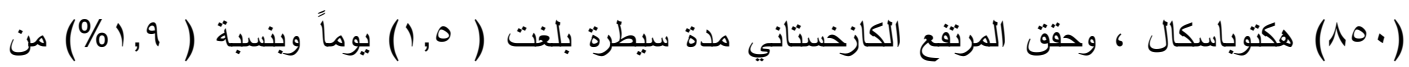
مجموع مدة سيطرة المنظومات الاخرى في المستوى (.... (1) هكتوباسكال الا انه لم يظهر في المستوى (10. ) هكتوباسكال. كما يظهر من الجدول المذكور سابقاً إن مرتفعي (شبه الجزيرة العربية ،الهضبة الايرانية) قد سجلا اقل مدة ظهور مقترنة بسيطرة الموجة المغلقة فقد بلغت مدة ظهورهما (يوما واحدا) كونت ما نسبته ( ب, (\%) من مجموع مدة سيطرة المنظومات الجوية الأخر عند المستوى الضغطي ( (... هكتوباسكال ويبدو ان مرتفع شبه الجزيرة لم يتعمق بخلاف مرتفع الهضبة الايرانية اذ سجل مدة ظهور بلغت 


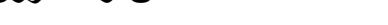

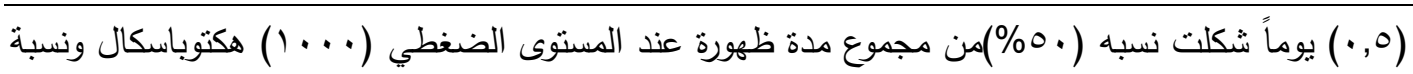

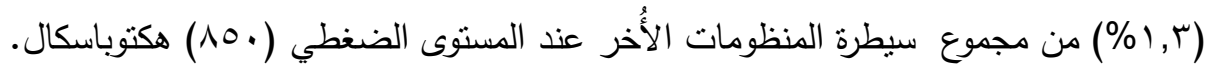

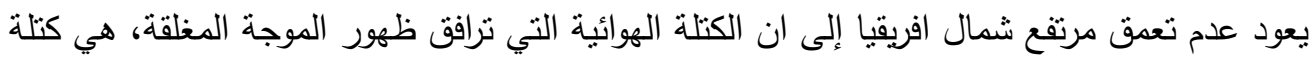

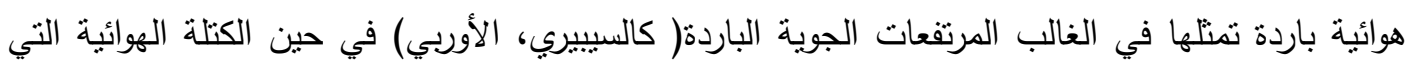

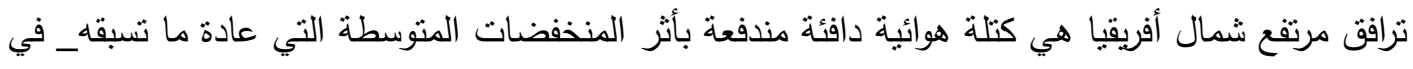

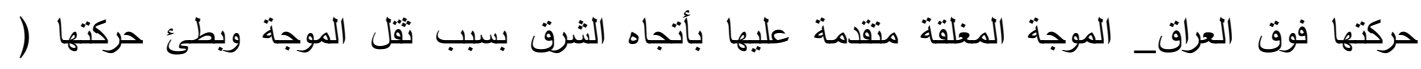

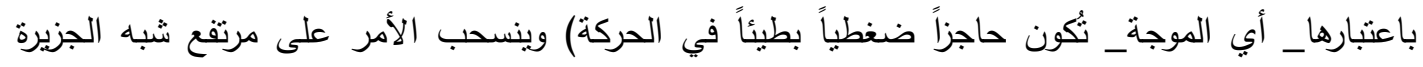

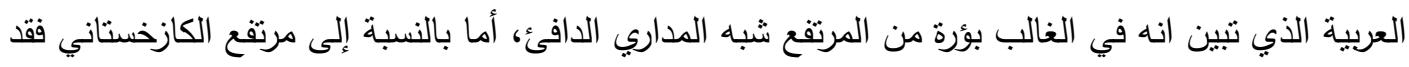

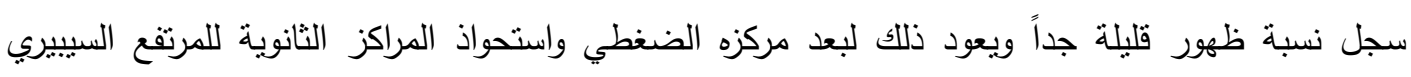
والاناضولي و مرتفع الهضبة الايرانية عليه.

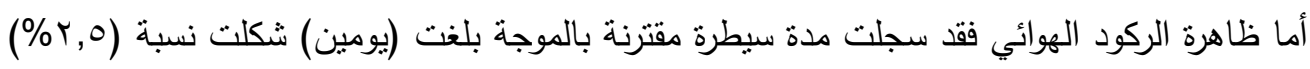

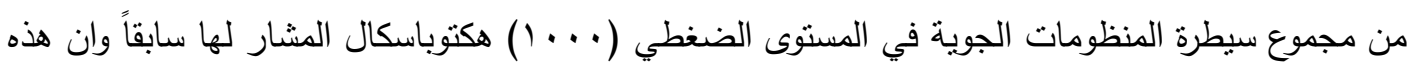

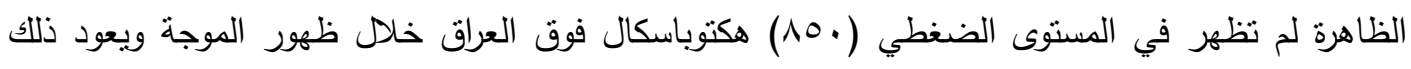

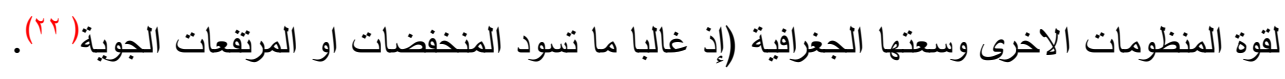

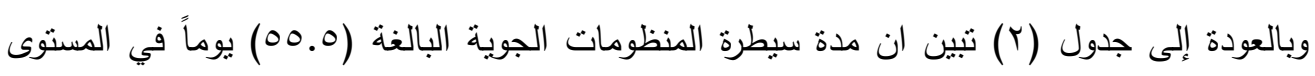

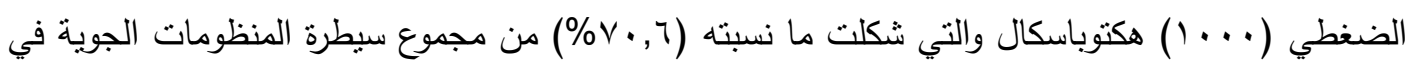

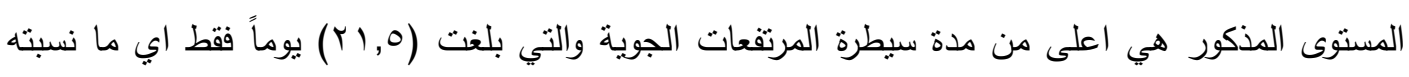
(إلى (YY,Y)

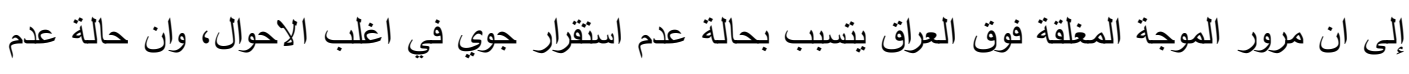

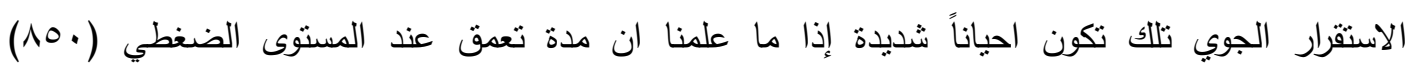

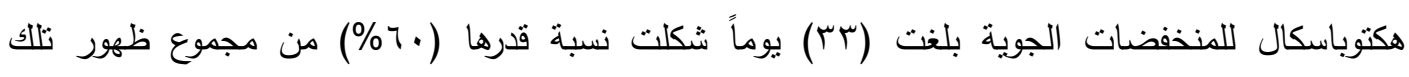

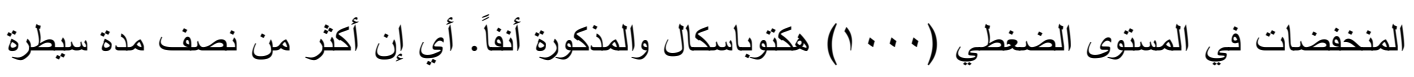

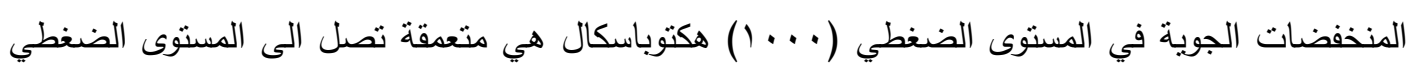


(10.) هكتوباسكال وهو ما قد يؤدي الى حدوث حالات طقسية متطرفة وبخاصة إنخفاض درجة الحرارة وتنساقط مطري كتيف ، كما اشرنا في صدر البحث.

ثالثاً : بعض النماذج الرصدية لحالات ظهور الموجة المغلقة فوق العراق وحالات اقترانها مع العات

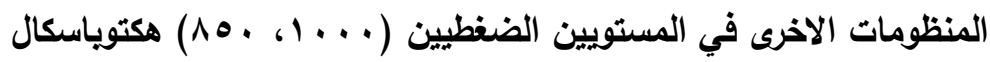

\section{(1) (النموذج}

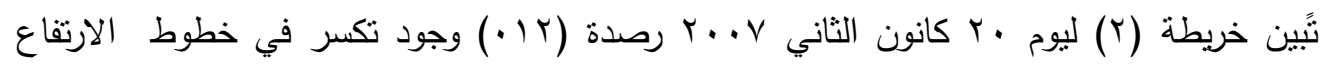
الجهدي وهو ما يشير إلى بداية تكون اخدود شرق البحر المتوسط وفي اليوم التالي تكون اخدود عميق

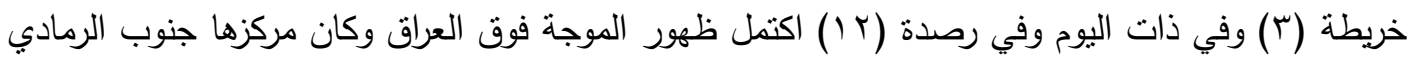

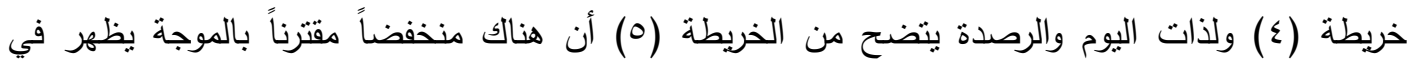

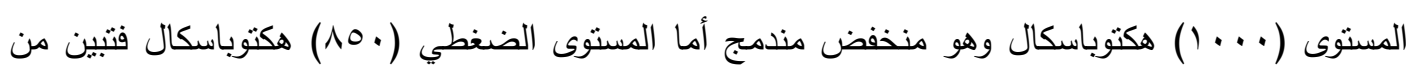
الخريطة (؟) منخفض مندمج يسيطر على أغلب الاراضي العراقية.

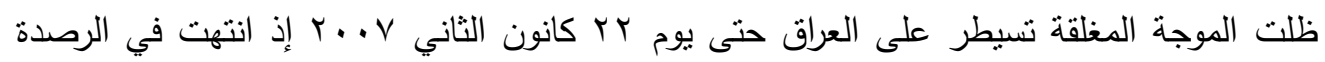

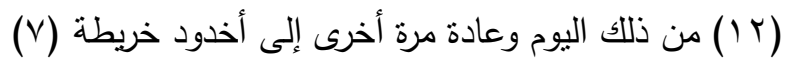


العــــــدد السادس والعشرون

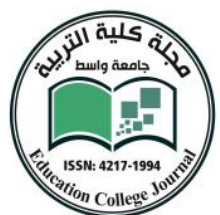

مجلــة كليـــة التربيـــة

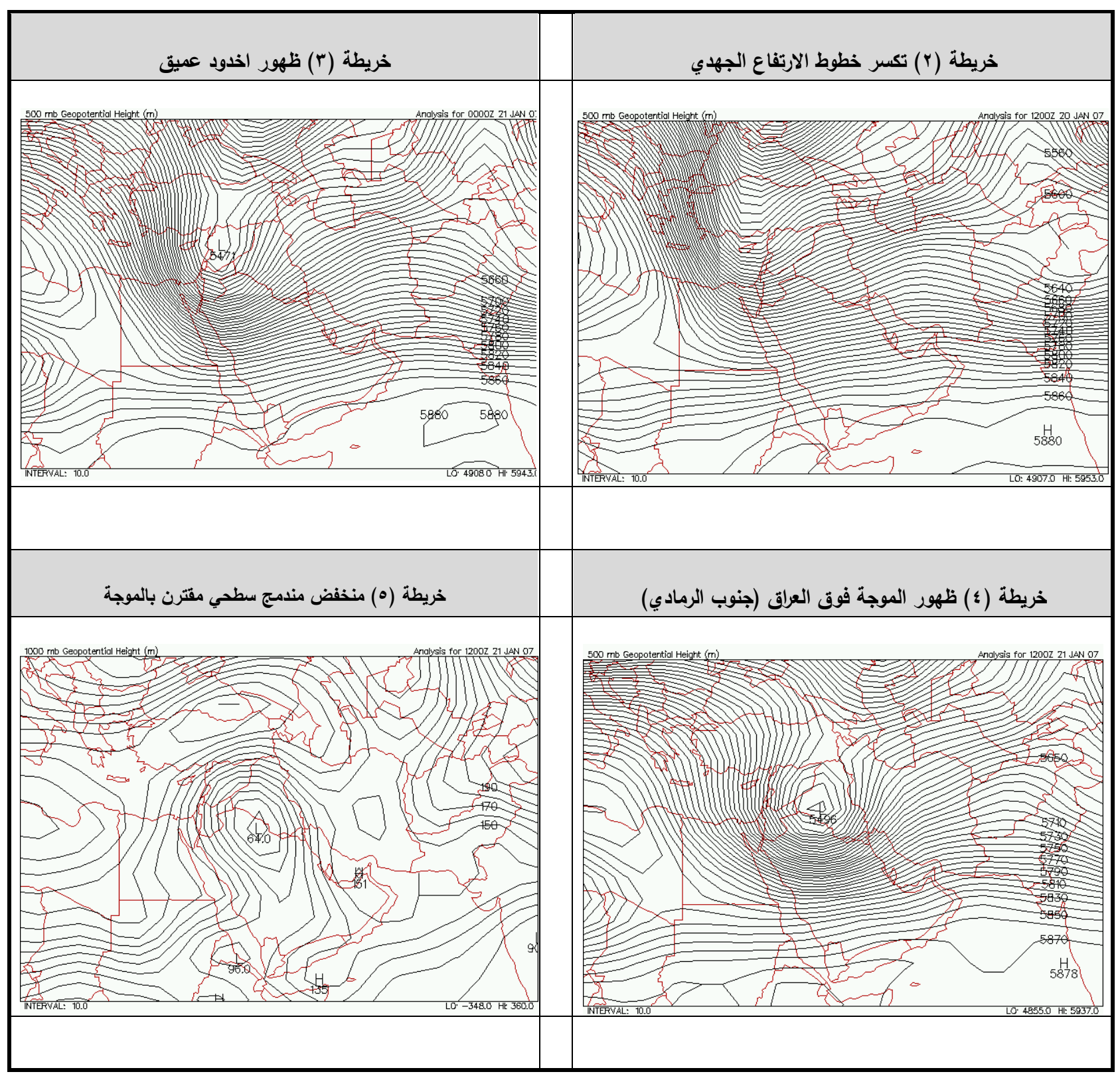




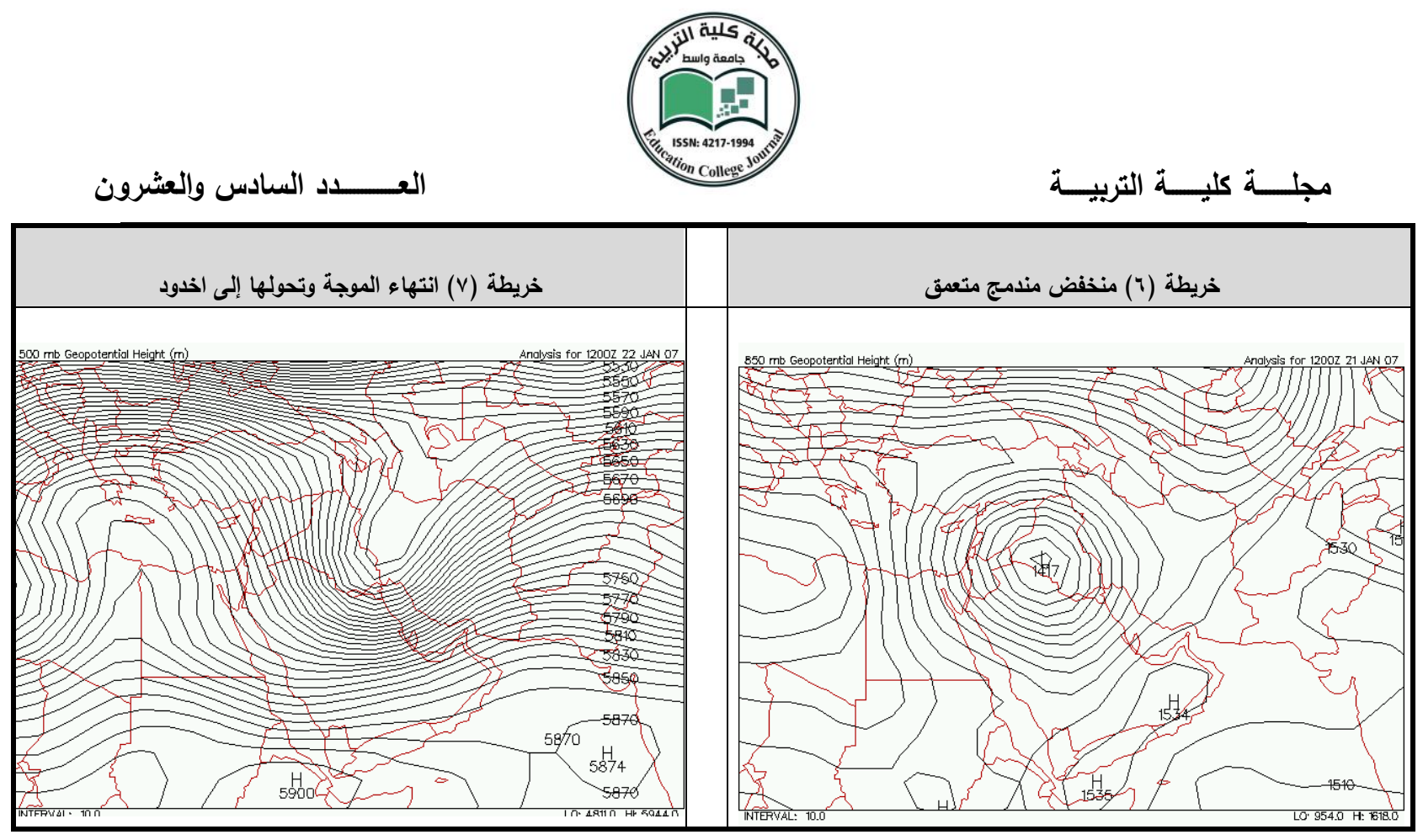

المصدر: الموقع الأكتروني: www.vortex plymouth.edu 


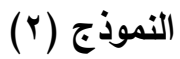

يتضح من الخريطة ( ^) ليوم • 1999/1// رصدة (ץ.) وجود أخدود هوائي فوق الأراضي

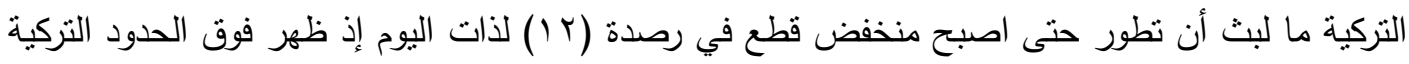

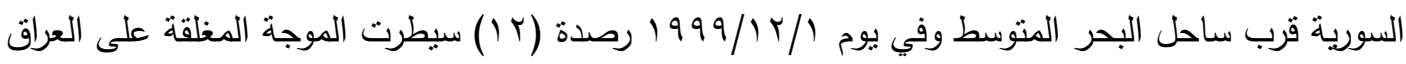

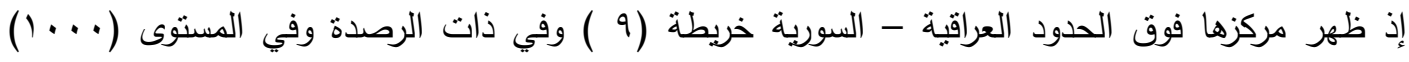

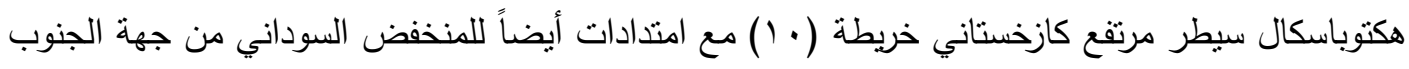

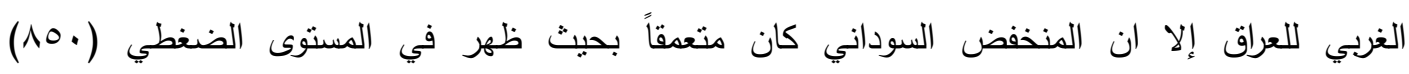
هكتوباسكال خريطة (1) وذلك لخفة وزن الكتلة الهوائية التي ترافقه كونها دافئة و رطبة لذان لذا تسلقت فوق

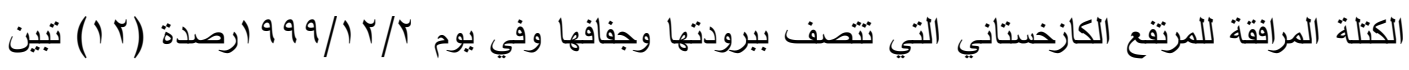

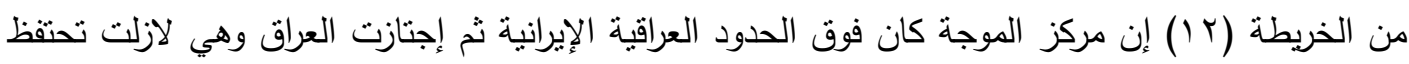
بقوتها ولم تتحول إلى أخدود هوائي. 

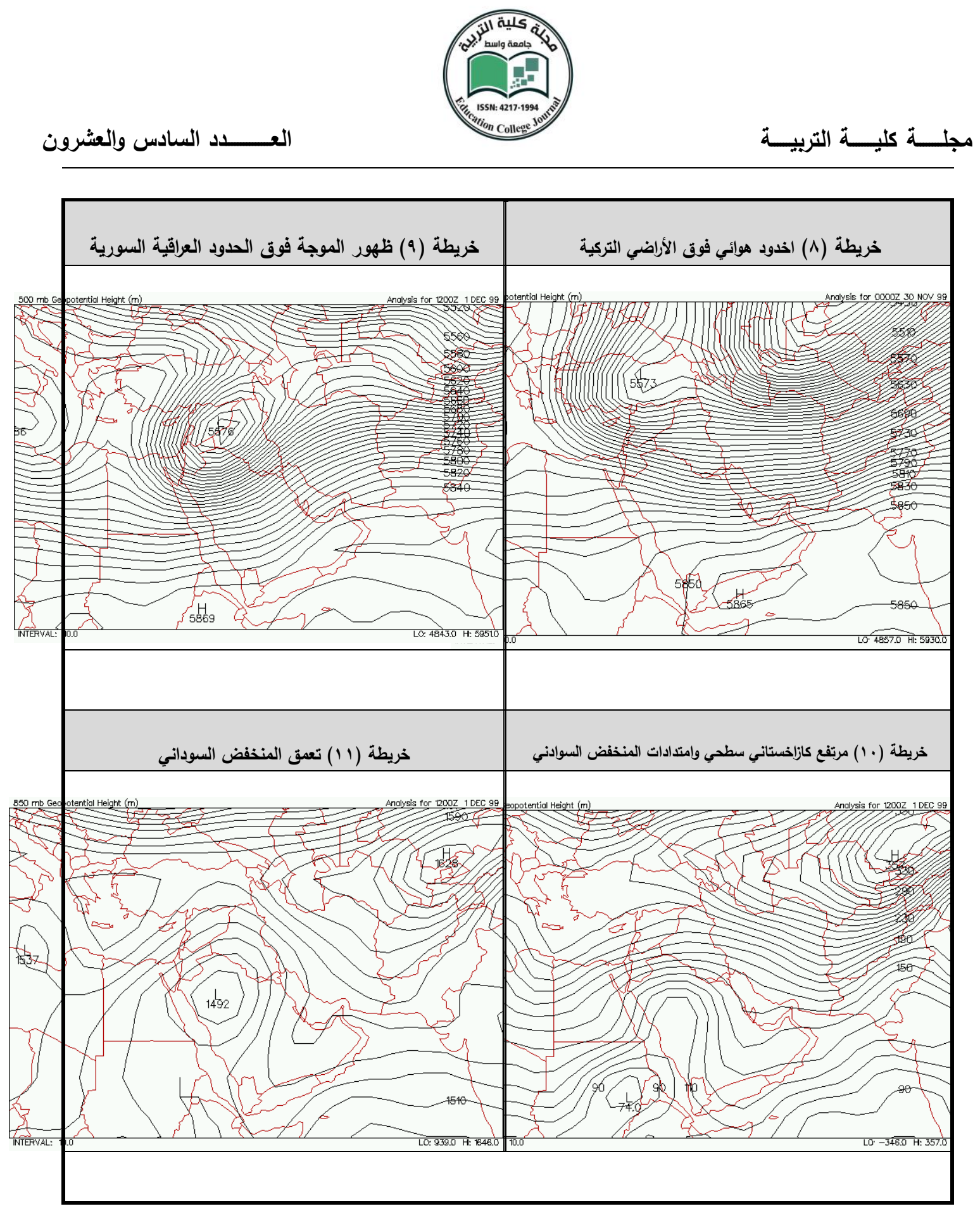


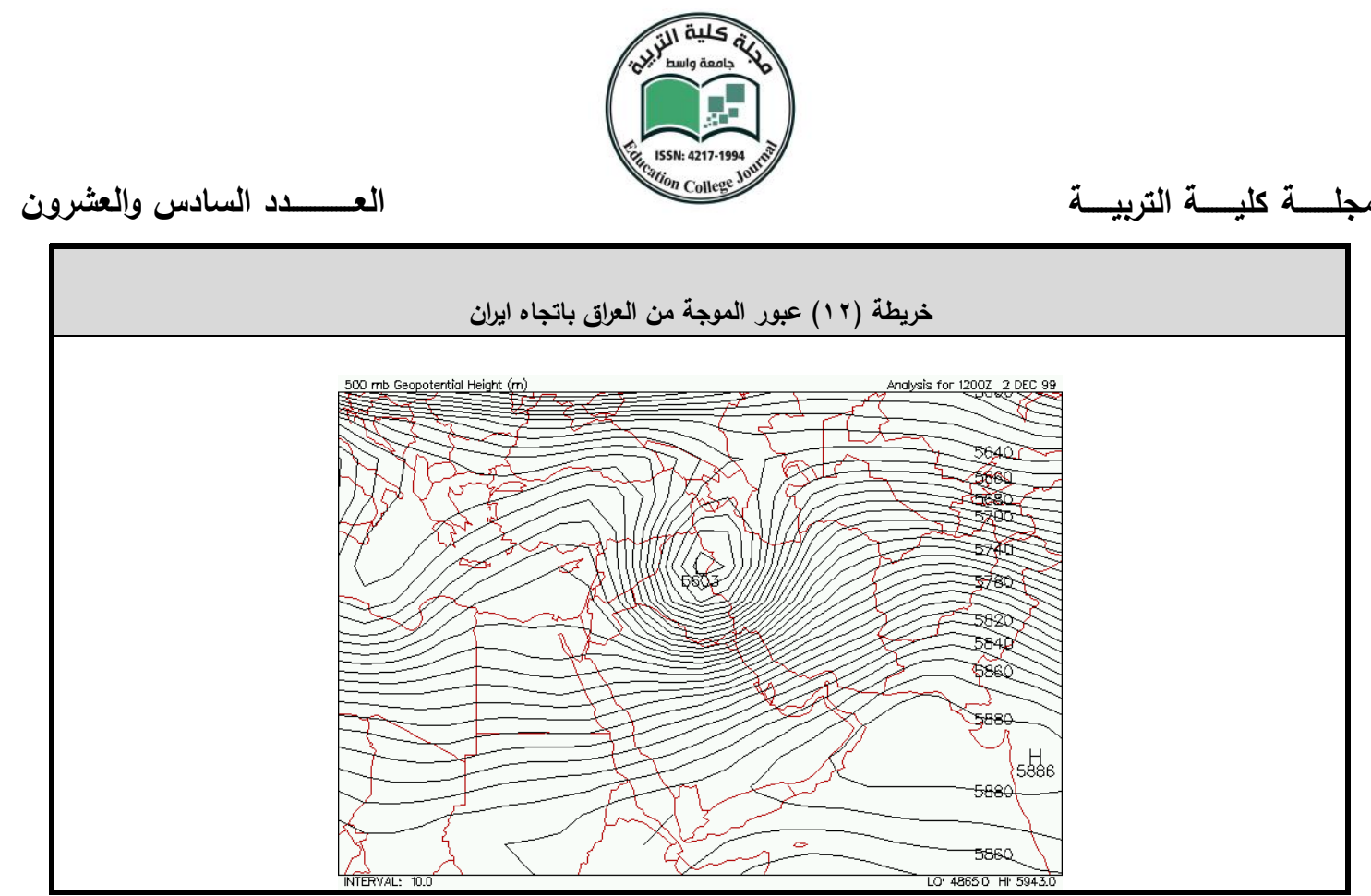

المصدر: الموقع الألكتروني: www.vortex plymouth.edu

\section{رابعاً : التغير في تكرار ومدة سيطرة الموجة المغلقة}

بغية تحقيق الهدف الأساسي من البحث والمتمنل بالتعرف على إتجاه التغير الحاصل في تكرار ومدة سيطرة الموجة المغلقة فوق العراق، فقد أعتمد الباحث على عدة وسائل للكثف عن ذلك الهدف وهي كالأتي:

\section{Moving Average استخدام أسلوب المتوسطات المتحركة}

إن تحديد اتجاه تكرار ومدة سيطرة الامواج المغلقة سيعطي تصوراً لواقع مناخ العراق الحالي والمستقبلي باعتبار الأمواج المغلقة أحد أهم الظواهر المناخية المؤثرة فيه ، كما ينبأ بإمكانية حدوث حالات تطرف مناخي فيه أيضاً وهو أهم اسنتناج يمكن إستخلاصه من الدراسة.

لقد جاء إستخدام اسلوب المتوسطات المتحركة كونه أكثر الأساليب الأحصائية لدراسة طبيعية التغيرات في العناصر والظواهر المناخية وهو يعمل على التخلص من الذبذبات المناخية القصيرة التي تعمل 
على تشويش الاتجاه العام(rr). لذلك فقد تم حساب وجمع المنوسطات التراكمية لكل خمسة سنوات للمدة

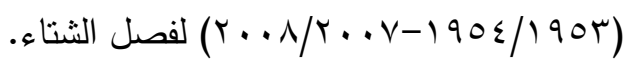

يظهر من خلال الثكل (r) أن هناك إتجاهاً نحو التزايد في تكرار الموجة المغلقة، خلال المدة الدذكورة في أعلاه، ولم تختلف مدة السيطرة للظاهرة قيد الدراسة عن الأتجاه الذي اتخذته تكراراتها، إذ يتضح من الثكل (ع) وجود أتجاه نحو النزايد أيضاً. 


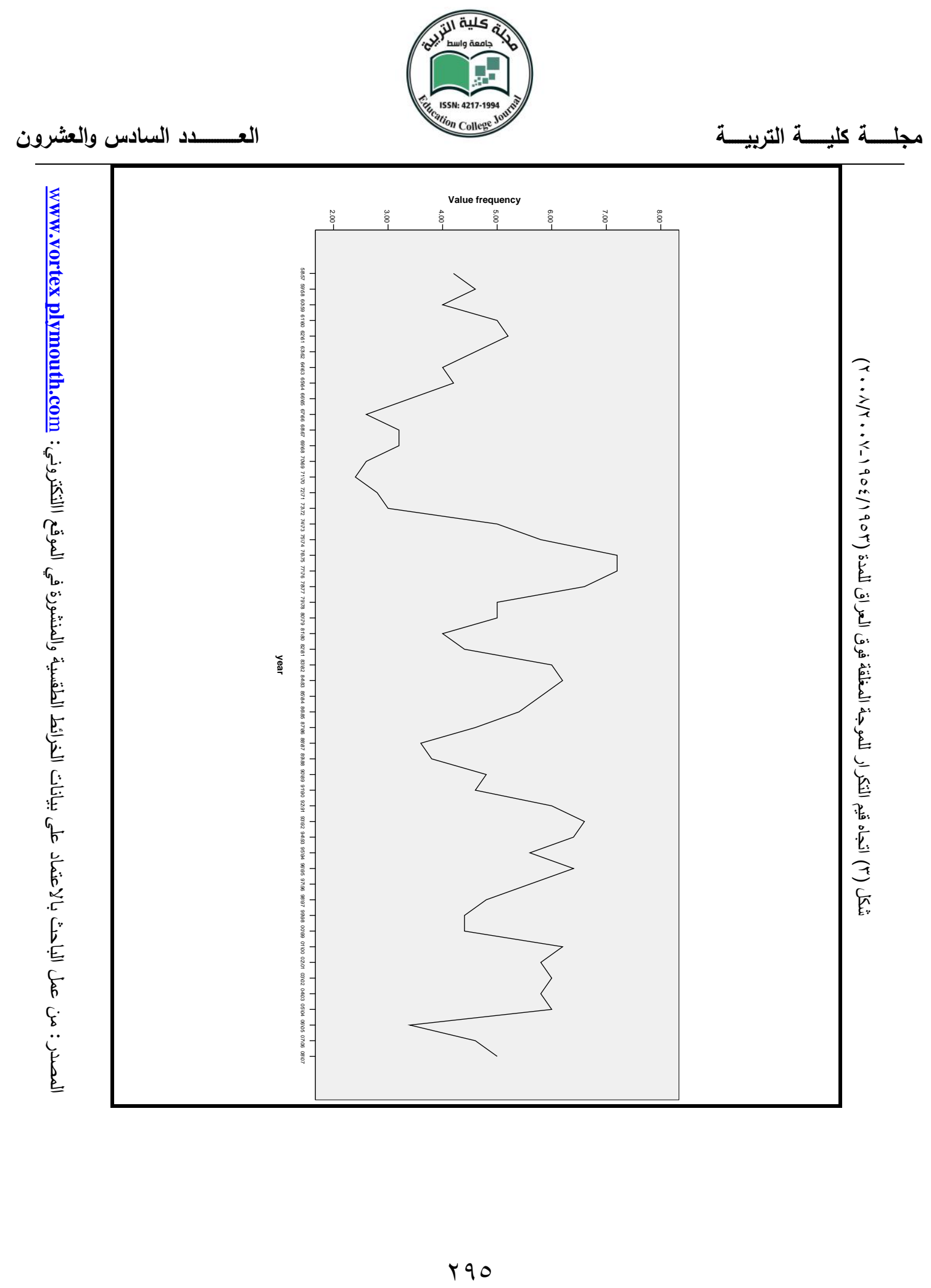




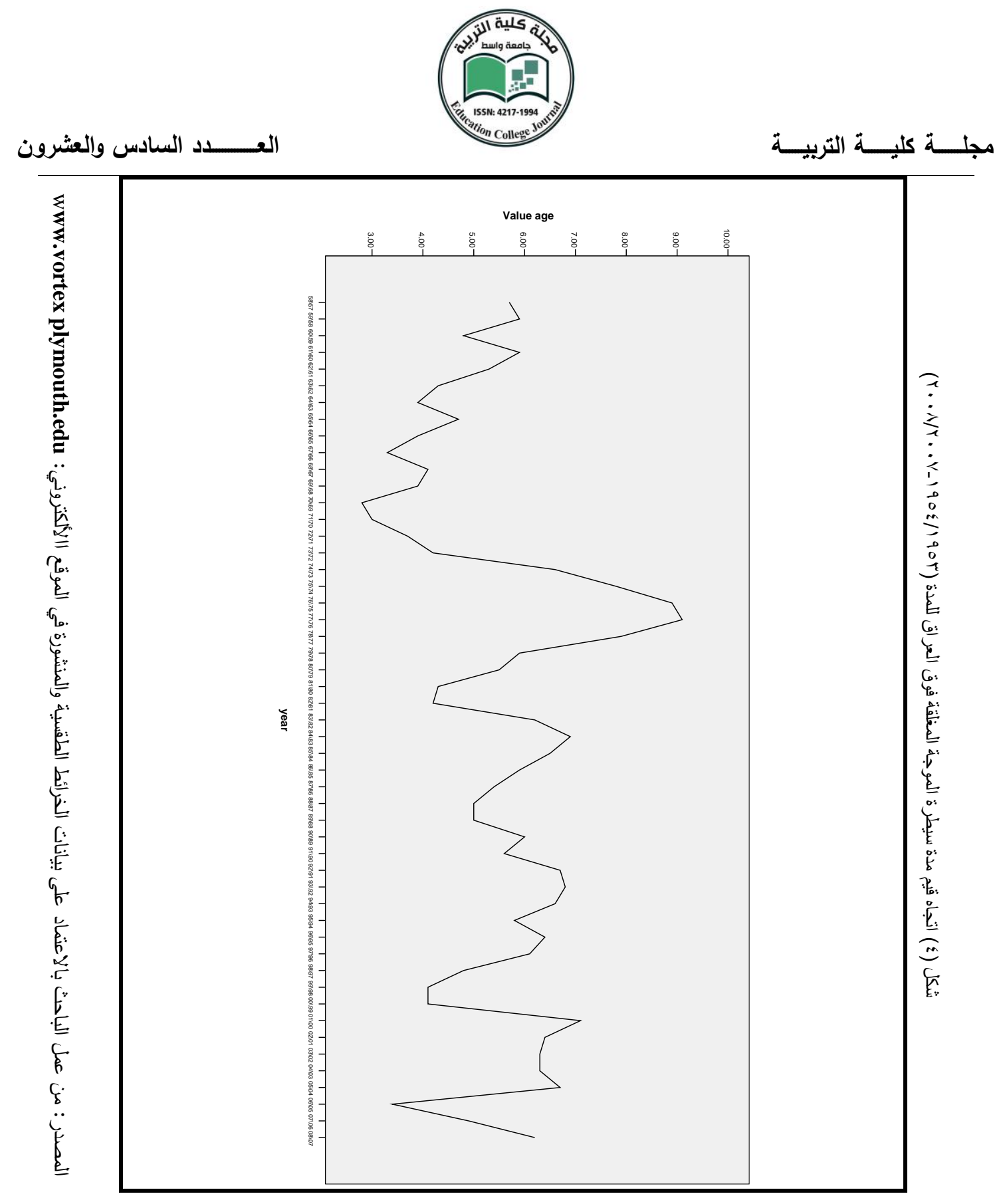


r - استخدام فروق المتوسطات ومعامل الاختلاف

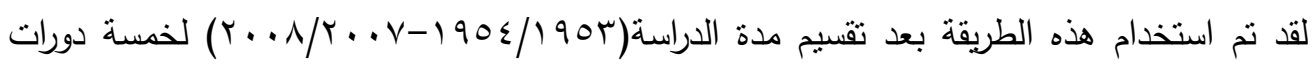

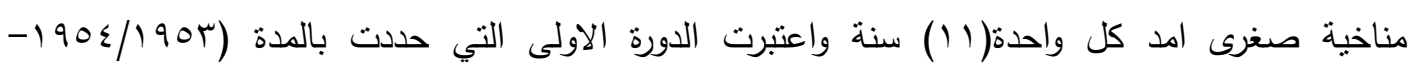

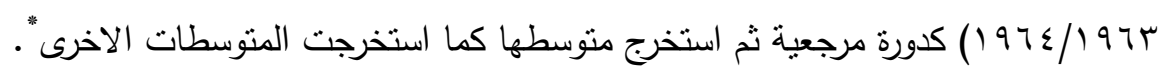

فضلاً عن ذلك استخراج معامل الاختلاف من الدورات الخمسة المذكورة انفاً ومن ثم تم اجراء عملية مقارنة بين الدورة الاولى والدورات الاربعة الاخرى لكل من فرق المتوسط ومعامل الاختلاف الذي يستخدم عادة لأغراض المقارنة مجموعتين أو أكثر، كما يمكن استخدام معامل الإختلاف لمعرفة مدى التجانس في قيم المجموعة، إذ كلما كان معامل الإختلاف اصغر كانت قيم المجموعة اكثر تجانساً والعكس صحيح(ءء).

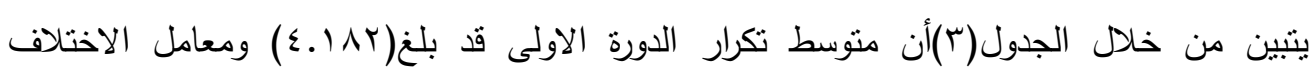

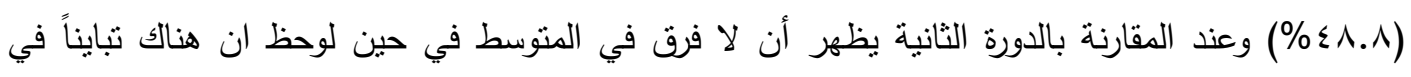
معامل الاختلاف لكل منها إذ بلغ معامل اختلاف الدورة الثانية (Y.79\%) وبذلك كون فرقاً في نسبة الاختلاف بلغ (ع. • r\%) هذا من جهة ومن جهة أخرى تبين أن الدورة الثانية اقل تجانساً في قيم نكراراتها من الدورة الأولى. كونها سجلت معامل اختلاف أكبر .

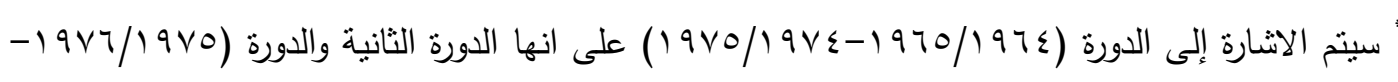

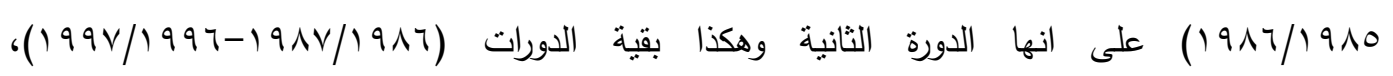

$$
\cdot(r \cdot N / r \cdot v-199 \Lambda / 199 v)
$$


جدول (r)

فروق متوسطات ومعاملات الاختلاف لقيم تكرار الموجة المغلة خلال فصل الثتاء فوق العراق لخمسة دورات مناخية صغرى

\begin{tabular}{|c|c|c|c|c|}
\hline فرق معامل الاختلاف \% & معامل الاختلاف \% & فرق المتوسط & المتوسط & الدورة \\
\hline \multirow{4}{*}{$r_{\cdot}, \varepsilon+$} & \multirow{2}{*}{$\varepsilon \wedge, \wedge$} & \multirow{4}{*}{-} & \multirow{2}{*}{$\varepsilon, 1 \wedge r$} & $190 \leqslant / 190 r$ \\
\hline & & & & $197 \leq / 1974$ \\
\hline & \multirow{2}{*}{$79, r$} & & \multirow{2}{*}{$\varepsilon, 1 \wedge r$} & $1970 / 197 \varepsilon$ \\
\hline & & & & $1980 / / 9 v \varepsilon$ \\
\hline \multirow{4}{*}{$r, 1+$} & \multirow{2}{*}{$\varepsilon \wedge, \wedge$} & \multirow{4}{*}{$1+$} & \multirow{2}{*}{$\varepsilon, 1 A T$} & $190 \leqslant / 190 r$ \\
\hline & & & & $197 \varepsilon / 1974$ \\
\hline & \multirow{2}{*}{$0 ., 9$} & & \multirow{2}{*}{$0,1 \wedge r$} & $1987 / 1980$ \\
\hline & & & & $1917 / 19100$ \\
\hline \multirow{4}{*}{$7, V-$} & \multirow{2}{*}{$\varepsilon \wedge, \wedge$} & \multirow{4}{*}{$1, r V T+$} & \multirow{2}{*}{$\varepsilon, 1 A r$} & $190 \leqslant / 190 r$ \\
\hline & & & & $197 \leqslant / 197 \%$ \\
\hline & \multirow{2}{*}{$\leq r, 1$} & & \multirow{2}{*}{$0, \leqslant 00$} & $1918 / / 917$ \\
\hline & & & & $1997 / / 997$ \\
\hline \multirow{2}{*}{$r, T$} & $\varepsilon \wedge, \wedge$ & \multirow{2}{*}{$1,1 \wedge r+$} & \multirow{2}{*}{$0, \Gamma \div \leq$} & $T \leqslant / T r /-0 \leqslant / 0 r$ \\
\hline & $v_{1}, \varepsilon$ & & & $\cdot 1 / \cdot v-91 / 9 v$ \\
\hline
\end{tabular}

المصدر: من عمل الباحث بالاعتماد على الخرائط المنشورة في الموقع الإكتروني: www.vortetplymouth.edu . وتطبيق معادلة المتوسط ومعامل الاختلاف

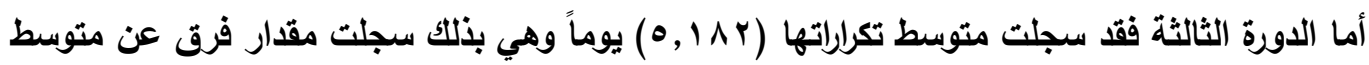
الدورة الأولى بلغ (+1) يوماً أما معامل اختلاف فقل سجلت نسبة معامل اختلاف بلغ (9 ه ، ه\%) مسجلاً

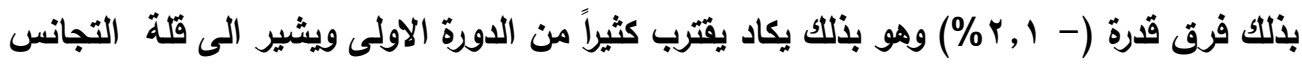
بالمقارنة مع الدورة الاولى. 


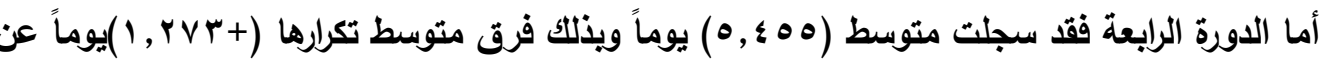

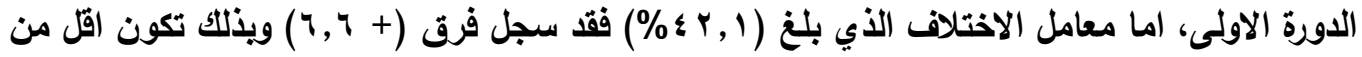
الدورة الاولى إلا ان معامل الاختلاف يثير إلى ان الدورة الرابعة هي اكثر تجانساً من الدورة الاولى.

لقد سجلت الدورة الخامسة متوسط تكرارات بلغ ( ؟ ب,ه) مسجلة بذلك مقدار تزايد عن متوسط تكرارات

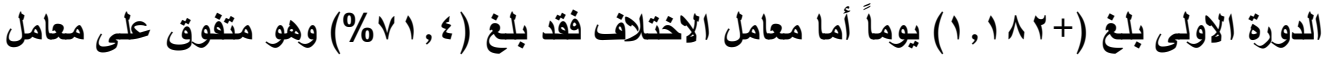

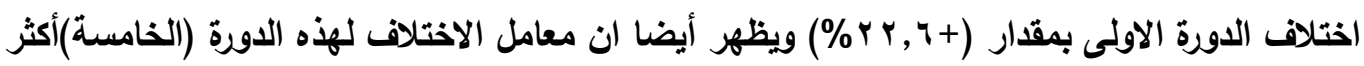
من كل الدورات السابقة مما يشير عدم تجانس كبير في قيم تكرارات الاورة وهو بالتالي يعني حصول حالات تطرف كتساقط الامطار الغزيرة أو انخفاض معدلات درجات الحرارة و تساقط الثلوج.

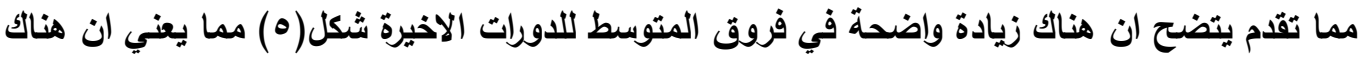

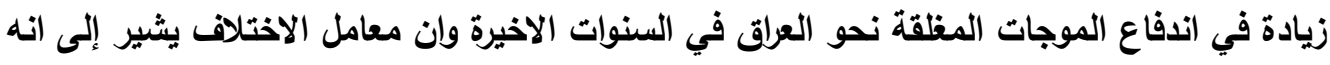

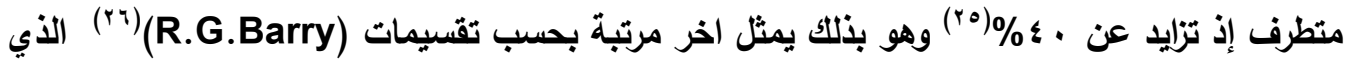
قسم معامل الاختلاف إلى سبع رتب وهذا يثير إلى تطرف تكرارات الموجة المظلقة فوق العرلق خلال مدة الادراسة. 
شكل (•)

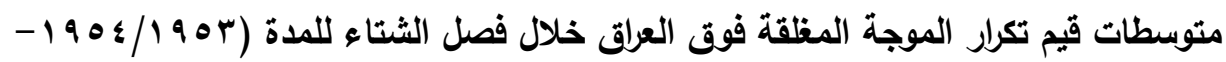

$$
(r . \wedge / r . . v
$$

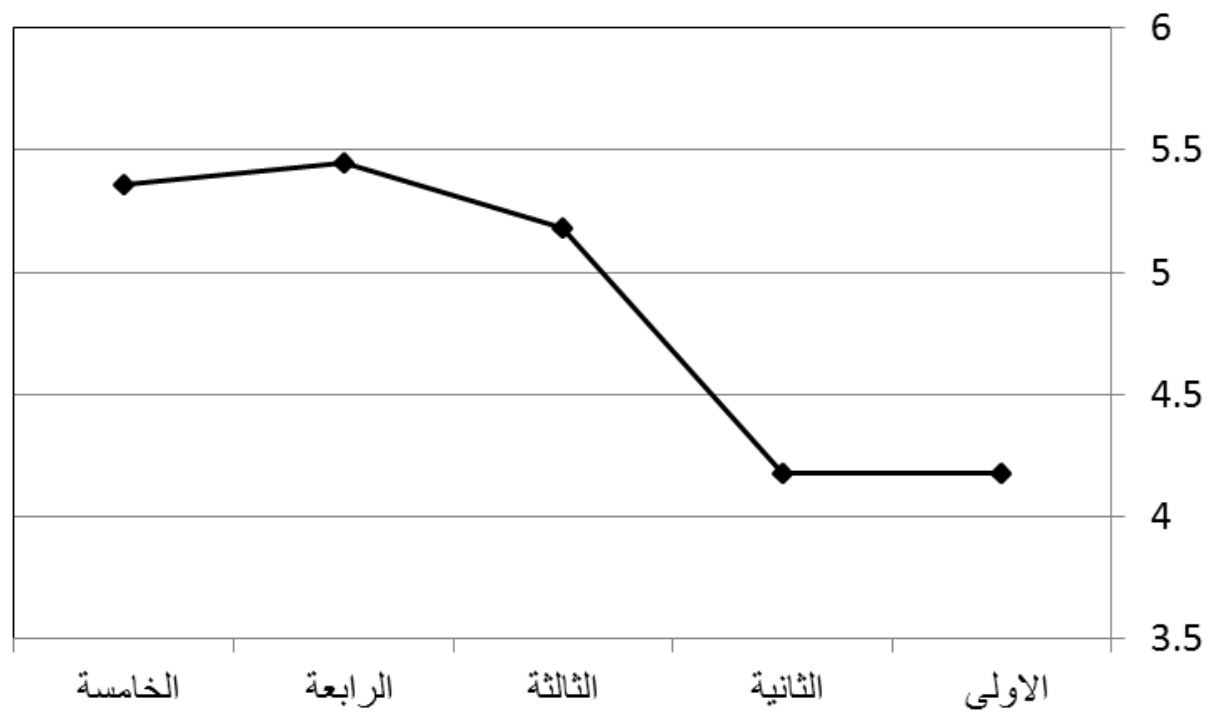

المصدر : من عمل الباحث بالاعتماد على بيانات الجدول (ॅ).

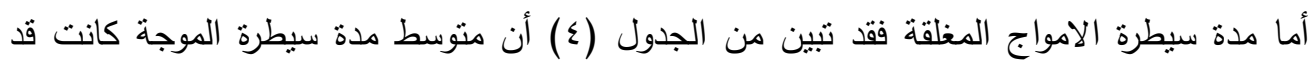

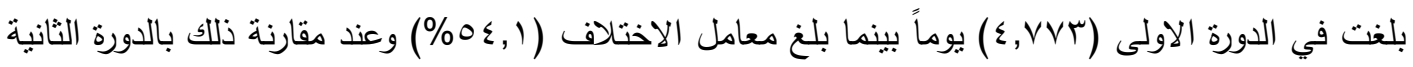

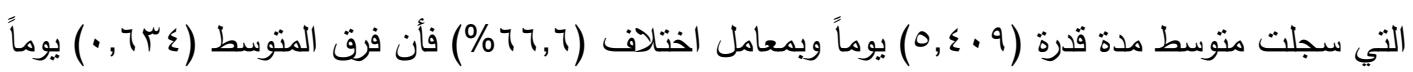

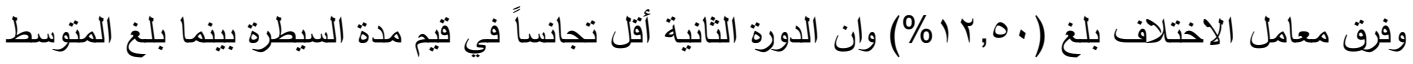

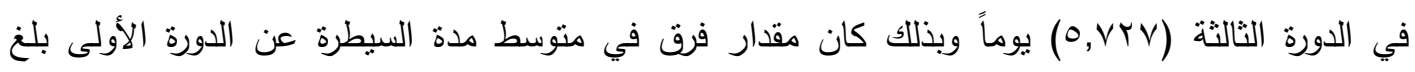

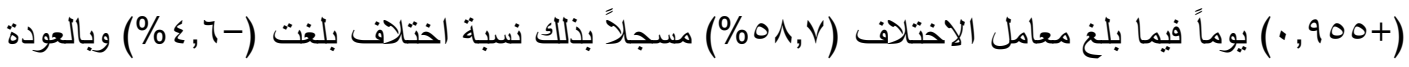


العـــــــد السادس والعشرون

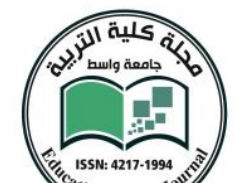

إلى معامل الاختلاف ايضاً يتضح ان مدة السيطرة في هذه الدورة - الثالثة - كانت أقل تجانساً في قيمها من قيم مدة السيطرة في الدورة الاولى.

جدول (๕)

فروق متوسطات ومعاملات الاختلاف لقيم مدة السيطرة الموجية المغلقة فوق لعراق لخمسة دورات مناخية صغرى

\begin{tabular}{|c|c|c|c|c|}
\hline فرق معامل الاختلاف & معامل الاختلاف \% & فرق المتوسط & المتوسط & الدورة \\
\hline \multirow{4}{*}{$1 Y, 0+$} & \multirow{2}{*}{$0 \leqslant, 1$} & \multirow{4}{*}{ +דו+ } & \multirow{2}{*}{$\varepsilon, V \vee r$} & $190 \leq / 190 r$ \\
\hline & & & & $197 \leqslant / 1975$ \\
\hline & \multirow{2}{*}{77,7} & & \multirow{2}{*}{$0, \varepsilon \cdot q$} & $1970 / 1978$ \\
\hline & & & & $19 \times 0 / 19 v \varepsilon$ \\
\hline \multirow{4}{*}{$\varepsilon, 7+$} & \multirow{2}{*}{$0 \leqslant, 1$} & \multirow{4}{*}{$\cdot, 900+$} & \multirow{2}{*}{$\varepsilon, \nabla V \Gamma$} & $190 \leqslant / 190 r$ \\
\hline & & & & $197 \leqslant / 1975$ \\
\hline & \multirow{2}{*}{$O \wedge, \vee$} & & \multirow{2}{*}{$0, V Y V$} & $19 \times 7 / 1980$ \\
\hline & & & & $1917 / 1910$ \\
\hline \multirow{4}{*}{$7,0-$} & \multirow{2}{*}{$0 \leqslant, 1$} & \multirow{4}{*}{$1, r \vee r+$} & \multirow{2}{*}{$\varepsilon, V \vee r$} & $190 \leqslant / 190 r$ \\
\hline & & & & $197 \leqslant / 1974$ \\
\hline & \multirow{2}{*}{$\varepsilon \vee, T$} & & \multirow{2}{*}{$7, \cdot \leq 0$} & $19 \wedge v / 1914$ \\
\hline & & & & $1998 / 1997$ \\
\hline \multirow{4}{*}{ r., q+ } & \multirow{2}{*}{$0 \leq, 1$} & \multirow{4}{*}{$1, r r V+$} & \multirow{2}{*}{$\varepsilon, V \vee r$} & $190 \leq / 190 r$ \\
\hline & & & & $1975 / 1974$ \\
\hline & \multirow{2}{*}{ ᄉт } & & \multirow{2}{*}{$7, \cdots$} & $1991 / 1998$ \\
\hline & & & & $r \ldots \wedge / r \ldots v$ \\
\hline
\end{tabular}

المصدر: من عمل الباحث بالاعتماد على الموقع الأكتروني: www.vortetplymouth.edu .

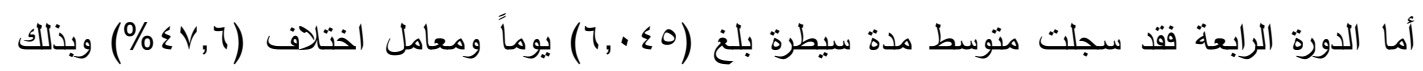

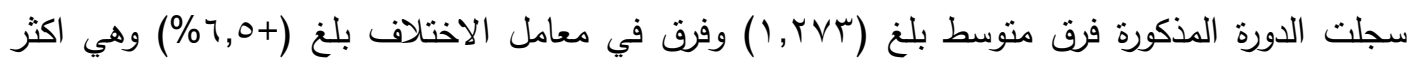


تجانساً في قيمها من ما تم تسجيلية في الدورة الاولى ويستمر تزايد فرق المتوسط ومعامل الاختلاف في

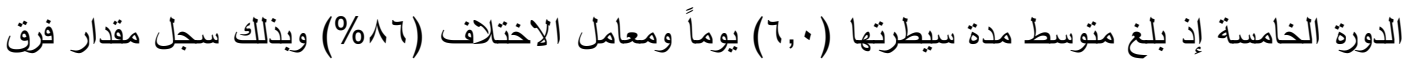

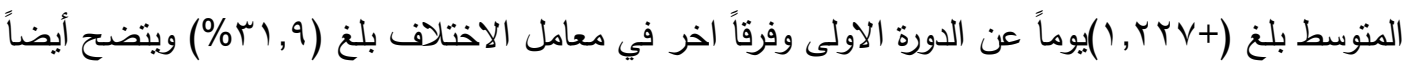

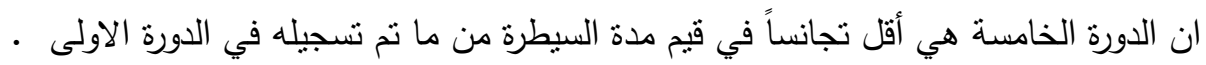

مما تقدم يظهر أن هناك زيادة في فروق المنوسط المسجلة في الدورات الأربعة وبالمقارنة مع الدورة الأولى

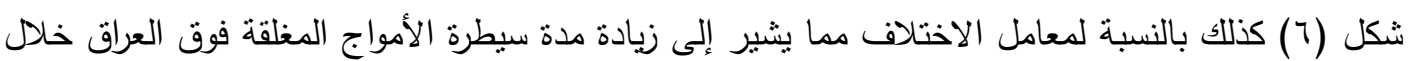

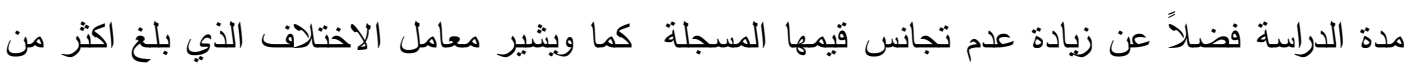
• • ع ايضا ان هناك تطرف في مدة السيطرة وبخاصة في السنوات الاخيرة .

\section{شكل (")}

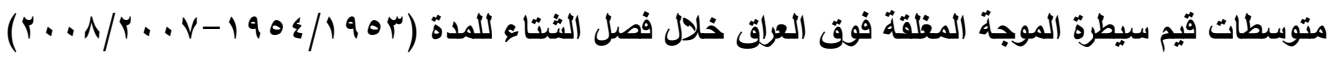

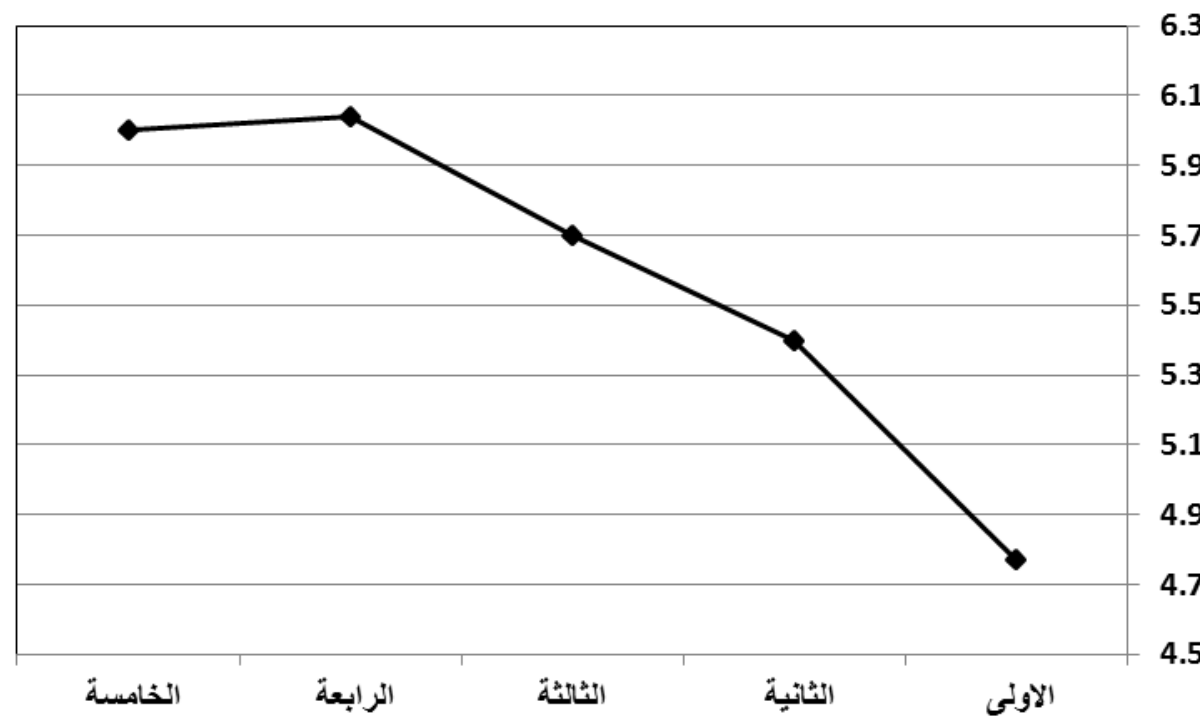

المصدر : من عمل الباحث بالاعتماد على بيانات الجدول ( ) .. 
خلاصة كل ما تقدم يتضح أن هناك تزايداً في تكرارات ومدة سيطرة الأمواج المغلقة فوق العراق خلال مدة الدراسة ككل وقد شهدت الدورة الخامسة اعلى معاملات الاختلاف وهي بذلك اقل الدورات تجانساً في قيم التكرارات ومدة السيطرة بعبارة اخرى يتضح ان هنالك تغيراً نحو التزايد والتطرف في حركة الأمواج وبناءاً على ذلك نتوقع نزايد حالات التطرف المناخي فوق العراق.

\section{خامسا : التنائج}

لقد تبين من خلال الدراسة النتائج التالية:

ا- أكثر المنظومات الضغطية التي يقترن ظهورها على السطح بالموجة المغلقة هي المنخفضات الجوية اذ

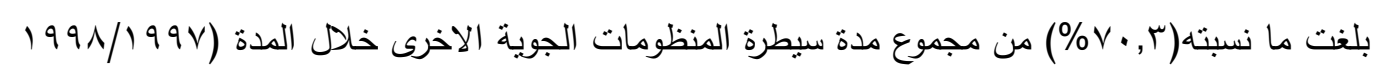

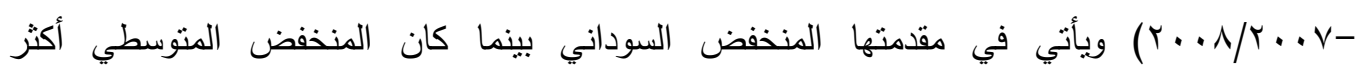

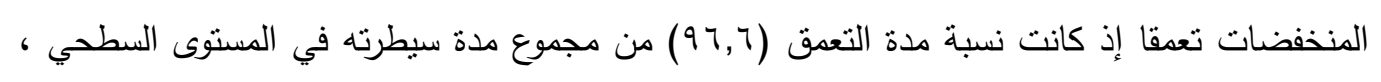
بعبارة اخرى ان غالبية الأيام التي تظهر فيها الموجة المغلقة فوق العراق يسود السطح حالة عدم استقرار جوي شديد، وتبين إن المرتفع السيبيري يأني في مقدمة المرتفعات الجوية السطحية المرافقة للموجة الهوائية وهو اكثرها تعدقا.

ץ- تبين وجود إتجاه نحو التزايد في تكرار ومدة سيطرة الموجة المغلقة (منخفض القطع) فوق العراق خلال

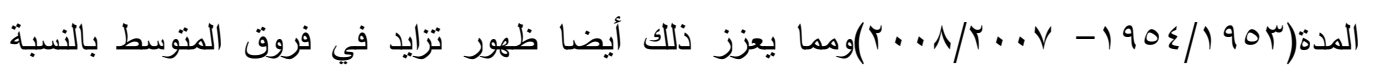
لتكرارات ومدة سيطرة الأمواج الهوائية للدورات قيد الدراسة كما ظهرت الدورة الخامسة بكونها اقل الدورات

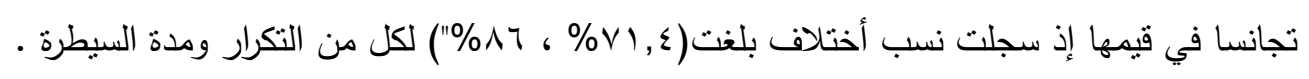
إن التزايد في تكرار ومدة سبطرة الأمواج المغلقة (منخفضات القطع) فوق العراق بدفعنا الى التوقع بأن حالات التطرف المناخي سنزداد مستقبلا فوق العراق وهو ما يتطلب وضع الحلول المناسبة للتقليل من الاثار البيئية السيئة المحتملة التي نرافق حالات التطرف في التساقط المطري والانخفاضات الحادة في درجات الحرارة وغيرها خلال فصل الثتاء. 


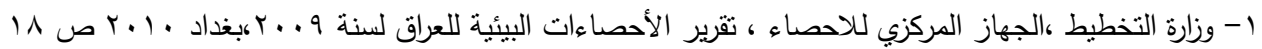

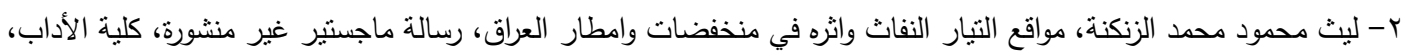

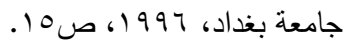

ب-يوسف محمد علي حانم الهزال، تكرار المنظومات الضغطية المختلفة واثرها في تباين قيمة الاشعاع الثنمسي الكلي وشفافية

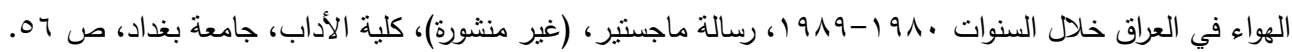

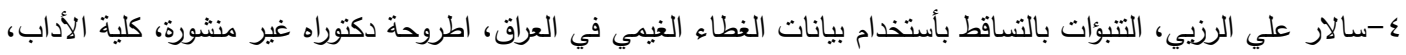

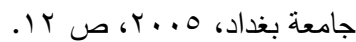

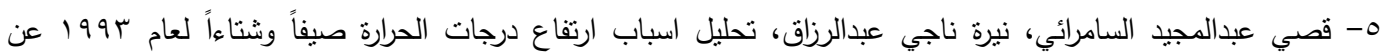

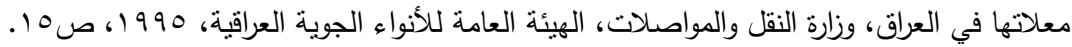
צ- حنين حاكم عبدالرضا، تأثير امواج روسي على مناخ العراق، رسالة ماجستير (غير منشورة)، كلية العلوم، الجامعة

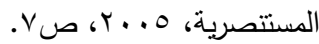

V-منصور غضبان بزاع الجوراني، اثر تغيير المناخ في حركة الاخاديد والاندماجات الهوائية المؤثرة في مناخ العراق، رسالة

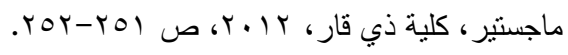

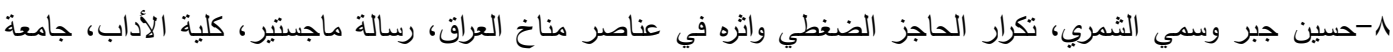

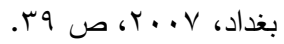

9- ماللك ناصر عبدالكناني، الامطار القياسية اليومية في العراق (دراسة شمولية) مجلة كلية التربية، جامعة ، مجلة كلية التربية،

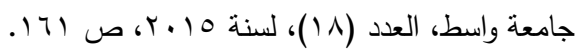

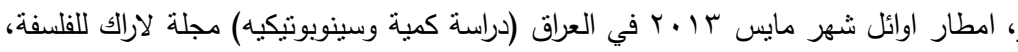
-1 .

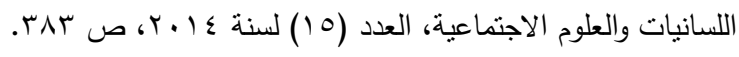

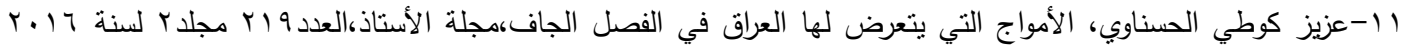
صro

12-kevin e.trenberth and john t.fasullo, climate extremes and climate change the Russian waves and other climate extreames 2010.journal of geophysical research.vol 1172012 p3

13 -Dim coumo and other, Quasi-resonant circulation regimes and hemispheric synchronization of extreme weather in boreal summer .pnas journal.vol. 111. No.34. p 12331

14- Dim coumo and other. The weakening summer circulation in the Northern Hemisphere Midlatitudes jorn. scince. Vol. 348.2015 p324.

15-www.arsco.org

17 1-عبدالغني جميل السلطان، الجو عناصره وتقلباته، دار الحرية للطباعة والنشر، بغداد، 910 1، ص ع ؛ (. 
V V-نعمة محسن الفتلاوي، خصائص المستوى ( . (0) هكتوباسكال فوق العراق والثرق الاوسط، مجلة علوم المستتصرية' مجلة

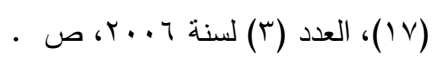

1 ا - فاتن عبدالباقي، ظواهر طبقات الجو العليا، واثرها في تثكيل وصياغة مناخ العراق، اطروحة دكتوراه (غير منشورة)، كلية

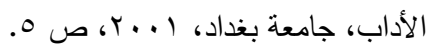

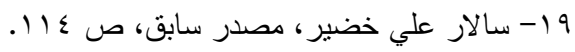

• ץ- علي شاكر النعيمي واخرون، التغير في كمية الامطار المصاحبة للمنظومات الجوية المؤثرة على القطر العراقي مجلة علوم

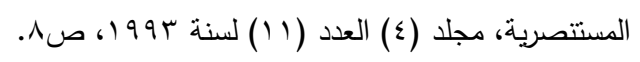

اب- علي غليس ناهي السعيدي، اثر تغير المناخ في تغيير المنظومات الثمولية السطحية المؤثرة في العراق خلال الفصل

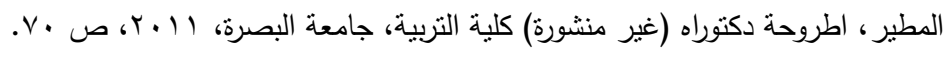

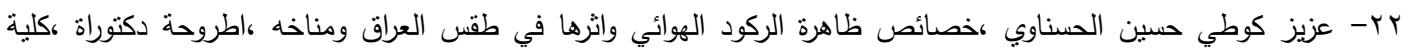

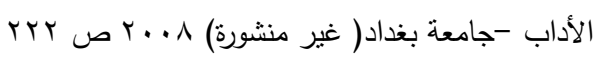

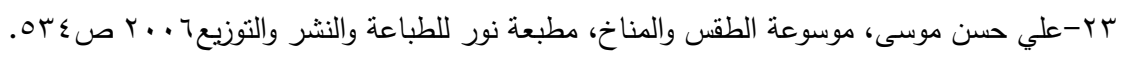

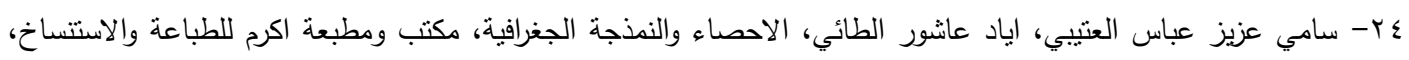

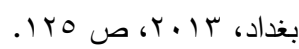

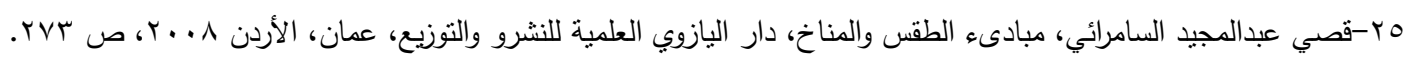
26-R. G. Barry, R.J. chorley, at mosphere, weather and climate, second edition, printed in Butter and Tanner LTD, Britain , 1972, P. 317. 


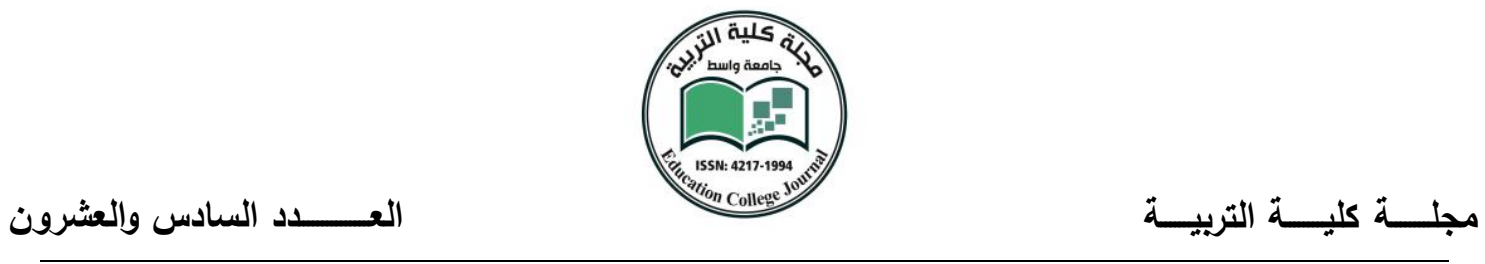

\section{Abstract}

This study has been dealt with the change of the blocking waves movement (cut off low) above Iraq during winter season. The aim was to discover the normality of these changes concerning (the date and the frequency of controlling times)

during the period (1953/1954) to (2007/2008).

By using the synoptic Maps Analysis of the pressure level (500) milibar of the dates mentioned and for the two weather forecast ' $(12,00)$. Also , by using "Moving Average" method and the coefficient of variation, Average difference, it has been found there is an increasing change of the waves movement of the periods mentioned previously.

These waves which have appeared above Iraq are accompanied by low atmosphere especially the Sudanese, the Medeterian and the Gulf.

During this study, it is expected there will be an increasing of extreme cases of raining severe cold temperatures.

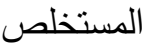

لقد تتاولت هذه الدراسة التغير في حركة الأمواج المغلقة(مراكز منخفضات القطع) فوق العراق خلال فصل

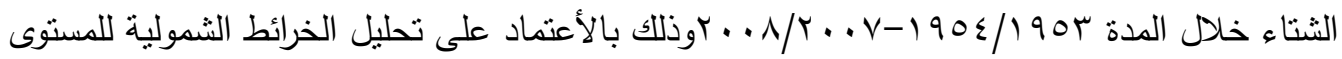

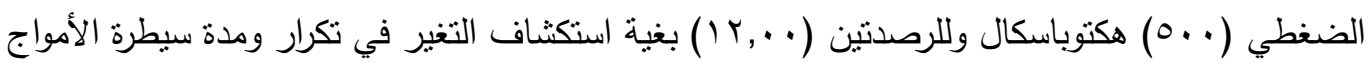
المغلقة (مراكز منخفضات القطع) فوق العراق وبأستخدام طريقة الأوساط المتحركة وفروق المتوسطات ومعامل الأختلاف ، وقد تبين وجود أتجاها نحو التزايد في نكرارات ومدة سيطرة مراكز القطع فوق منطقة

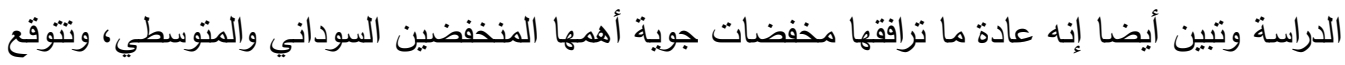

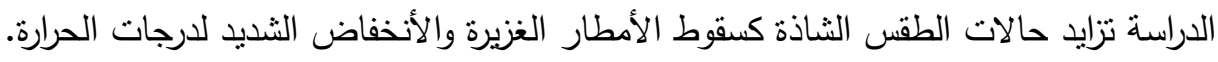

